\title{
Mountain torques and synoptic systems in the Mediterranean
}

\author{
Joseph Egger ${ }^{a}$ and Klaus-Peter Hoinka ${ }^{b}$ \\ ${ }^{a}$ Meteorologisches Institut der Universität München, Germany \\ b Institut für Physik der Atmosphäre, DLR, Oberpfaffenhofen, Germany
}

\begin{abstract}
The mountains surrounding the Mediterranean exert torques T during the passage of North Atlantic systems which affect the angular momentum of the airflow passing over and around the massifs. The Alps, the Atlas range and the orographic block of Asia Minor are selected to investigate the typical flow conditions during torque events. These mountain ranges are small enough to justify a local angular momentum analysis. Both the zonal and the meridional components of a mountain's torque $\left(T_{\lambda}\right.$ and $\left.T_{\varphi}\right)$ are used as stratification parameters in a statistical investigation of the interaction of large-scale perturbations with this mountain. How are these flows affected by the obstacle? A simple scheme is tested which attempts to interpret results.

The torque analysis singles out eastward-moving large-scale systems. Their isobars are oriented from southwest (northwest) to northeast (southeast) near the mountain in zonal torque $T_{\lambda}\left(T_{\varphi}\right)$ cases. The massifs tend to generate a low-level distortion of the pressure field such that the angular momentum of the flow over the mountain is reduced. These results can be explained within the framework of the scheme. The influence of the mountains on the pressure field is seen only at heights $\leq 4000 \mathrm{~m}$. The low-level distortions of the pressure field contribute positively to the total torque for lags $\tau \leq 0$ in the Alps and for all lags $-2 \leq \tau \leq 2$ days in Asia Minor, where only $T_{\lambda}$ is evaluated. The impact of the Atlas mountains is seen only at $\tau=0$. Copyright (C) 2008 Royal Meteorological Society
\end{abstract}

KEY WORDS angular momentum; Alps; Atlas mountains; Asia Minor

Received 25 May 2007; Revised 5 March 2008; Accepted 14 March 2008

\section{Introduction}

The Mediterranean basin is surrounded by impressive mountain ranges, e.g. the Pyrenees, the Alps and the Atlas mountains in the west and the mountains of Asia Minor and of the Lebanon in the east. All these massifs affect the synoptic systems entering the Mediterranean from outside and also, of course, those which originate in the region. For example, Saharan cyclones (Sharav cyclones; Alpert and Ziv, 1990) are generated in the lee of the Atlas mountains and then move eastwards. Moreover, all these mountains shield the Mediterranean to some extent from cold air outbreaks and affect the precipitation pattern. In particular, mountains exert torques on the angular momentum of the airflow over and around them. More specifically, the torque exerted by a mountain describes the transfer of angular momentum from the Earth to the atmosphere due to the pressure distribution at the mountain slopes. (Section 2 gives definitions and formulae.) Observed typical torques at the mountain ranges to be considered are 1-2 Hadley (1 Hadley $=10^{18} \mathrm{~J}$; Table I). Accelerations (decelerations) of $\sim 10 \mathrm{~m} \mathrm{~s}^{-1}$ per day have to be expected if such torques act on the momentum of the airflow above a mountain of $1000 \mathrm{~km}$ zonal length and $200 \mathrm{~km}$ meridional width. Although there is no reason

\footnotetext{
* Correspondence to: Joseph Egger, Meteorologisches Institut der Universität München, Theresienstr. 37, 80333 München, Germany.

E-mail: J.Egger@lrz.uni-muenchen.de
}

why the action of the torques should be felt only above the mountain, it is obvious that large amounts of momentum are transferred during torque events. Field campaigns like the Pyrenees Experiment (PYREX; Bougeault et al., 1993) have been conducted to investigate such events in the Pyrenees in detail. We are not aware, however, of climatological work on torque events in the Mediterranean. To fill this gap, we report here on statistical analyses of torque events in the Alps, the Atlas range and Asia Minor. All these massifs are zonally oriented so that we expect to find some similarity of corresponding events. On the other hand, their locations with respect to the Mediterranean basin differ so widely that interesting variations must be expected.

This problem will be approached by correlating mountain torques with flow observations. This is a conventional technique. Weickmann (2003), for example, applied it to the Tibetan Plateau and the massifs of North America with respect to axial torques (2.2). He found a pronounced response of the atmospheric flow to these mountains (Iskenderian and Salstein, 1996). Egger and Hoinka (2006) correlated flow analyses in the Greenland domain with this massif's axial torque. Our approach differs from this work in that we choose a strictly local framework (section 2) which allows us to calculate the impact of the mountain both on the meridional and the zonal components of the flow across the obstacle. In particular, precipitation will be included because it implies 
Table I. Seasonal mean mountain torques $T_{\lambda}, T_{\varphi}$ and related standard deviations $\sigma_{i}$ (units: Hadley) for the Alps, Asia Minor and the Atlas range.

\begin{tabular}{|c|c|c|c|c|c|}
\hline & & Mar-May & Jun-Aug & Sep-Nov & Dec-Feb \\
\hline \multirow[t]{2}{*}{ Alps } & $T_{\lambda \mathrm{AL}}$ & $0.1 / 1.2$ & $-0.2 / 0.9$ & $0.2 / 1.2$ & $0.2 / 1.5$ \\
\hline & $T_{\varphi \mathrm{AL}}$ & $-0.1 / 0.9$ & $-0.3 / 0.6$ & $0.0 / 0.9$ & $-0.1 / 1.1$ \\
\hline Asia Minor & $T_{\lambda \mathrm{AM}}$ & $-0.5 / 1.7$ & $-2.3 / 1.4$ & $-1.1 / 1.9$ & $0.2 / 2.2$ \\
\hline \multirow[t]{2}{*}{ Atlas } & $T_{\lambda \mathrm{AT}}$ & $-1.6 / 1.4$ & $-2.3 / 1.0$ & $-0.9 / 1.2$ & $0.1 / 1.3$ \\
\hline & $T_{\varphi \mathrm{AT}}$ & $-0.6 / 1.1$ & $-0.6 / 0.7$ & $-0.2 / 0.9$ & $-0.3 / 1.2$ \\
\hline
\end{tabular}

1 Hadley $=10^{18} \mathrm{~J}$.

$T_{\lambda}$ data only are given for Asia Minor for reasons discussed in the text.

interesting feedbacks on the torques. For example, orographic lifting may lead to release of latent heat. The related warming generally implies a decrease of the surface pressure at the upslope which thus affects the torque.

It must be stressed that such a covariance analysis lumps together many different flow situations. For example, events of lee cyclogenesis in the Alps involve the generation of torques because of the large pressure gradients observed there during such flow sequences. However, a high located above Central Europe also induces torques in the Alps. Both types of event contribute to the statistics but it would be futile to learn much about either type of synoptic situation from a torque-based covariance analysis. Instead, the covariance technique produces a typical flow sequence which may be reminiscent of observed synoptic evolutions as in Weickmann (2003) and Egger and Hoinka (2006). This is also the case in the Mediterranean, as will be seen.

This paper is organized as follows. The notion of local torques is introduced in section 2 where also a simple scheme is proposed regarding the relation of torques and flows across a mountain. The data are described in section 3. The result of the statistical evaluations for the Alps, the Atlas mountains and Asia Minor are given in section 4.

\section{Local torques}

As is well known (De Viron et al., 1999), the torque $\mathbf{T}$ exerted by a mountain on the angular momentum of the atmosphere has three components, two equatorial ones $\mathrm{T}_{1}, \mathrm{~T}_{2}$ and the axial component $\mathrm{T}_{3}$ so that

$$
\mathbf{T}=T_{1} \mathbf{i}_{1}+T_{2} \mathbf{i}_{2}+T_{3} \mathbf{i}_{3}
$$

where the basic unit vector $\mathbf{i}_{1}$ points from the Earth's centre to the 'Greenwich point' $\lambda=0, \varphi=0$, while $\mathbf{i}_{2}$ is rotated by $90^{\circ}$ to the east (Figure 1). The axial vector $\mathbf{i}_{3}$ is aligned with the Earth's rotation axis. The axial torque

$$
T_{3}=-\int_{F} p_{\mathrm{s}} \frac{\partial h}{\partial \lambda} \mathrm{d} f
$$

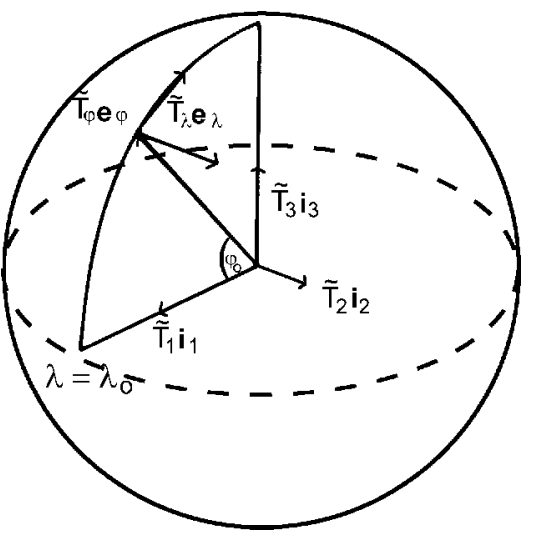

Figure 1. Torque vector components $\tilde{T}_{j} \mathbf{i}_{j}$ and the local components $\tilde{T}_{\lambda} \mathbf{e}_{\lambda}, \tilde{T}_{\varphi} \mathbf{e}_{\varphi}$ for a mountain located at longitude $\lambda_{\mathrm{o}}=0$ and latitude $\varphi_{\mathrm{o}}$.

captures essentially the east-west surface pressure difference across the mountain where $h$ is topography, $p_{\mathrm{s}}$ is the surface pressure and $F$ is an area covering the obstacle ( $\mathrm{d} f$ is a surface element).

The equatorial torques are

$$
\begin{aligned}
T_{1,2}=\int_{F} p_{s}\left\{\frac{\partial h}{\partial \varphi} \cos \varphi\left(\begin{array}{c}
-\sin \lambda \\
\cos \lambda
\end{array}\right)\right. \\
\left.+\frac{\partial h}{\partial \lambda} \sin \varphi\left(\begin{array}{c}
\cos \lambda \\
\sin \lambda
\end{array}\right) a^{2}\right\} \mathrm{d} \lambda \mathrm{d} \varphi
\end{aligned}
$$

(e.g. Egger et al., 2007) with $a$ as the radius of the Earth. These mountain torques act on the angular momentum $\mathbf{m}$ of the airflow passing over and around the mountains. It is a key point that the horizontal extent of the mountains considered here is fairly small so that $\lambda \sim \lambda_{\mathrm{o}}$ and $\varphi \sim \varphi_{\mathrm{o}}$ are good approximations in (2.2) and (2.3) where $\left(\lambda_{0}\right.$, $\left.\varphi_{0}\right)$ are the mean longitude and latitude of the mountain. Correspondingly we may replace $(\lambda, \varphi)$ in (2.2) and (2.3) by $\left(\lambda_{0}, \varphi_{\mathrm{o}}\right)$ to obtain the 'local' mountain torques $\tilde{T}_{i}$. Combination of (2.2) and (2.3) gives

$$
\sin \varphi_{0} \tilde{T}_{3}=-\cos \varphi_{0}\left(\tilde{T}_{1} \cos \lambda_{0}+\tilde{T}_{2} \sin \lambda_{0}\right) .
$$

The term in the brackets represents the equatorial components of the mountain torque exerted by this obstacle at longitude $\lambda_{0}$. The axial torque must be proportional to this equatorial one, as can also be found by simple geometrical considerations. We may choose $\lambda_{0}=0$ to see easily that (2.4) also expresses the fact that the local mountain torque is tangential to the Earth's surface at the location $\left(\lambda_{0}, \varphi_{0}\right)$ (Figure 1). This finding is not surprising because this torque acts on the specific local angular momentum $\mathbf{m}=\mathbf{r} \times \mathbf{v}_{\mathrm{a}}$ which is tangential as well. Here, $\mathbf{r}$ is the position vector pointing from the Earth's centre to $\left(\lambda_{0}\right.$, $\left.\varphi_{\mathrm{o}}\right)$ and $\mathbf{v}_{\mathrm{a}}$ is the absolute flow velocity. Thus

$$
\mathbf{m}=-a \rho v \mathbf{e}_{\lambda}+a \rho \cos \varphi_{0}\left(\mathrm{u}+a \Omega \cos \varphi_{0}\right) \mathbf{e}_{\varphi},
$$

where $\mathbf{e}_{\lambda}\left(\mathbf{e}_{\varphi}\right)$ is the unit vector of the standard spherical coordinate system pointing eastward (northward) (Figure 1) and $(u, v)$ is the horizontal flow velocity at 
$\left(\lambda_{\mathrm{o}}, \varphi_{\mathrm{o}}\right)$ which may depend on the height $z$. The density is $\rho$. A transformation of the torque vector $\tilde{\mathbf{T}}$ to this local system yields, with (2.4),

$$
\begin{aligned}
& \tilde{T}_{\lambda}=-\tilde{T}_{1} \sin \lambda_{0}+\tilde{T}_{2} \cos \lambda_{0}, \\
& \tilde{T}_{\varphi}=-\left(\begin{array}{lll}
\tilde{T}_{1} \cos \lambda_{0}+\tilde{T}_{2} \sin \lambda_{0}
\end{array}\right) / \sin \varphi_{0},
\end{aligned}
$$

and finally, with (1.3),

$$
\begin{aligned}
& \tilde{T}_{\lambda}=\int_{F} p_{\mathrm{s}} \frac{\partial h}{\partial \varphi} \cos \varphi_{0} a^{2} \mathrm{~d} \lambda \mathrm{d} \varphi, \\
& \tilde{T}_{\varphi}=-\int_{F} p_{\mathrm{s}} \frac{\partial h}{\partial \lambda} \cos \varphi_{0} a^{2} \mathrm{~d} \lambda \mathrm{d} \varphi .
\end{aligned}
$$

Thus $\tilde{T}_{\varphi}=\tilde{T}_{3}$ and $\tilde{T}_{\lambda}$ follows from (2.9) by rotation. These local torques are depicted in Figure 1. We chose this somewhat circumstantial derivation of (2.8) and (2.9) because the actual torque calculations in this paper are based on the correct formulae (2.2) and (2.3) in order to have the correct torques available for any further analysis. Correspondingly we use, for example, the local Alpine torques

$$
\begin{aligned}
& T_{\lambda \mathrm{AL}}=-T_{1} \sin \lambda_{0}+T_{2} \cos \lambda_{0}, \\
& T_{\varphi \mathrm{AL}}=-\left(T_{1} \cos \lambda_{0}+T_{2} \sin \lambda_{0}\right) / \sin \varphi_{0},
\end{aligned}
$$

where $T_{1}$ and $T_{2}$ are the correct equatorial Alpine torques (2.3). The same way, local torques $T_{\lambda \mathrm{AT}}, T_{\lambda \mathrm{AM}}$, etc. are defined for the Atlas mountains and Asia Minor.

In what follows we will correlate the torque components (2.10) and (2.11) with flow observations in the Mediterranean. This analysis will tell us, for example, which synoptic situations are typical for zonal torque events in the Alps.

There have been two rather different theoretical approaches to explain the torques exerted by mountains. Lejenäs and Madden (2000) calculated large-scale wave modes on the basis of a linear dynamical model. These modes propagate zonally with a phase speed derived from the model and induce a torque through their surface pressure if a mountain is assumed in the wave domain. The wave is not affected by the mountain in this type of approach. Alternatively, the torque due to the large-scale field is assumed to be of no concern, but the atmospheric response to the presence of the mountain is calculated explicitly. Inertia-gravity waves, baroclinic waves and even Rossby waves can be excited by and radiate away from this mountain (Smith, 1979; Held, 1983) both vertically and horizontally (Egger, 1998). This radiation results in a torque such that the angular momentum of the mean flow is reduced. For example, westerly flow over a mountain will generate a surface pressure perturbation with high pressure on the windward side and low pressure in the lee. The related axial (meridional) torque is negative and removes axial angular momentum. Most of this work on orographically induced perturbations is conducted in a time-independent framework which is at best partly relevant to our problem. Time-dependent aspects are dealt with by Speranza et al. (1985), Trevisan et al. (1988), Orlanski and Gross (1994) and others who calculated eigenmodes of baroclinic models for a given topography (also Buzzi and Tosi, 1989). Although all this work is not concerned with torques, the results show clearly that the mountain-induced flow modifications involve torques which change in time.

It is not only mountain-induced waves which can exert a torque. For example, shallow cold fronts are blocked and deformed by the Alps such that a high-pressure tongue will protrude eastward along the northern flank of the Alps (e.g. Egger and Hoinka, 1992; Orlanski and Gross, 1994). Clearly, a torque $T_{\lambda \mathrm{AL}}<0$ is exerted in this case.

The theoretical work quoted above is not concerned with the distinction between zonal and meridional torques nor does it provide a clue for which situations such torques are to be expected. However, (2.8) and (2.9) contain the basic rule that $\tilde{T}_{\lambda}\left(\tilde{T}_{\varphi}\right)$ is positive if the surface pressure is relatively high on the southern (eastern) slope of an obstacle compared to the northern (western) one. We can refine this statement by separating the impact of the large-scale field on the torque from that of the flow's reaction to the mountain. We look at zonally elongated mountains as selected in this paper underneath an eastward-moving large-scale system. The scale of this feature is assumed to be larger than the zonal extent of the mountain. Its orientation is of crucial importance.
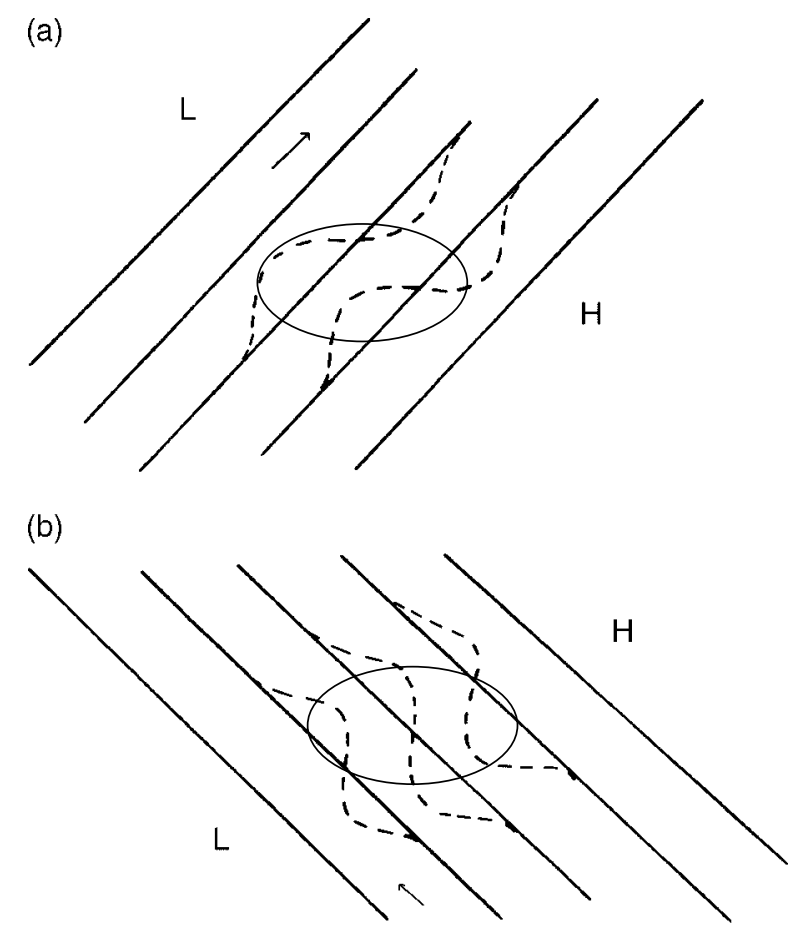

Figure 2. Schematic showing the expected surface pressure distribution near a zonally elongated mountain underneath a large-scale pressure trough field: (a) trough $\mathrm{L}$ in the northwest and high $\mathrm{H}$ in the southeast, and (b) ridge $\mathrm{H}$ in the northeast. The solid lines depict the surface isobars of the large-scale field to be expected if there were no topography. The adjustment of the surface pressure distribution to the presence of the mountain is given by the dashed lines. The arrows denote the large-scale wind. 
(a)

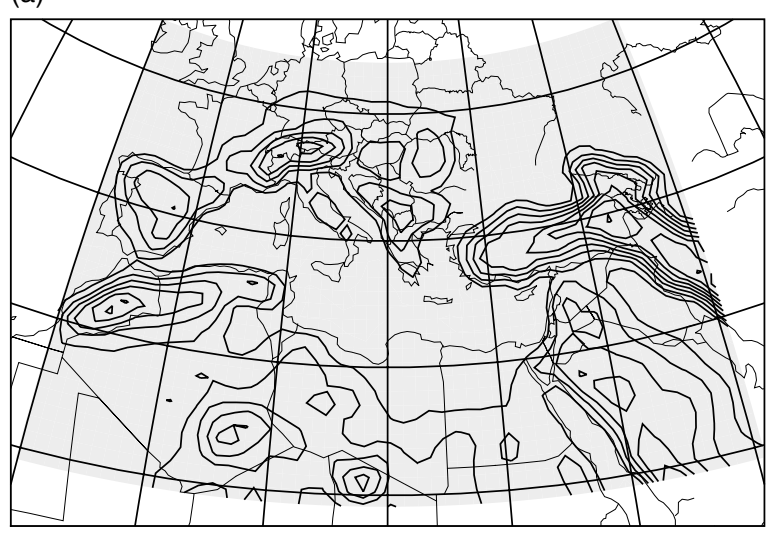

(b)

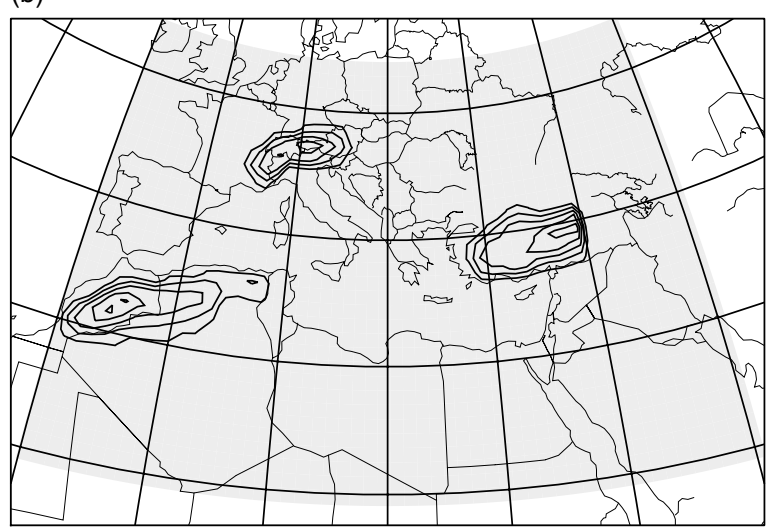

Figure 3. Topographies: (a) ERA-40 orography and (b) modified orography as used in the torque calculations. The contour interval is $250 \mathrm{~m}$, and the grey shading denotes the analysis area.

Let us first (Figure 2(a)) assume a southwest-to-northeast oriented pressure field so that the induced near-surface winds across the mountain are southwesterly. Following Lejenäs and Madden (2000), we estimate the contribution of the large-scale wave to the torque by inserting the related surface pressure field in (2.8) and (2.9). Clearly $T_{\lambda}^{*}>0, T_{\varphi}^{*}>0$ where the star refers to the large-scale pressure field. The mountains tend to resist the airflow over them via the torque. Since $\mathrm{m}_{\lambda} \sim-v<0$ (2.5) we must expect that the perturbation-induced torque $\hat{T}_{\lambda}$ 
These covariances (also called regressions) are threedimensional fields except for precipitation. The mean locations $\left(\lambda_{\mathrm{o}}, \varphi_{\mathrm{o}}\right)$ used are $\left(10.0^{\circ} \mathrm{E}, 46.5^{\circ} \mathrm{N}\right)$ for the Alps, $\left(1.5^{\circ} \mathrm{W}, 32.5^{\circ} \mathrm{N}\right)$ for the Atlas mountains, and $\left(34.0^{\circ} \mathrm{E}\right.$, $39.0^{\circ} \mathrm{N}$ ) for Asia Minor.

Standard significance tests have been performed on a local grid point basis. It is found that the significance is fairly high because of the large number of data entering these calculations. It must be stressed, however, that the evaluation of the significance of fields would have to take into account that neighbouring grid points are statistically dependent (e.g. Livezey and Chen, 1983). Projection on relatively few basic functions like empirical orthogonal functions is needed to solve this problem. Conducting such tests would have been extremely costly. Nevertheless, statistical significance appears not to be a key issue here.

It is of interest to compute the contribution of various layers to the statistical 'mean' torque

$$
Q_{\lambda}=-\int_{F} C\left(T_{\lambda}, p_{\mathrm{s}} \mid \tau\right) \frac{\partial h}{\partial \lambda} \mathrm{d} f
$$

exerted by the surface pressure covariances with respect to a massif as a function of lag. We choose in (3.1) the zonal torque but analogous formulae are valid for $Q_{\varphi}$. The integral $Q_{\lambda}$ at $\tau=0$ would equal the standard deviation $\sigma_{\lambda}$ of $T_{\lambda}$ (Table I) if all torque events had the same surface pressure distribution (except for sign and amplitude). The contribution of all layers above a height $z=z_{\mathrm{o}}$ to $(3.1)$ is

$$
Q_{\lambda}\left(z_{0}\right)=-\int_{F} C\left(T_{\lambda}, p\left(z_{0}\right) \mid \tau\right) \frac{\partial h}{\partial \lambda} \mathrm{d} f
$$

where $p\left(z_{0}\right)$ is the pressure at $z=z_{0}$. Problems arise when $z_{0}$ is below the mountain height because areas with $h>z_{0}$ are then excluded from the integration. In particular, $Q_{\lambda}(0)=0$ at the bottom. The evaluation of (3.2) allows us to distinguish reasonably well between the contribution of the large-scale field to the torques and that of the low-level flow deformations. If, for example, $Q_{\lambda}\left(z_{1}\right) \sim Q_{\lambda}\left(z_{2}\right)$ where $z_{1}\left(z_{2}\right)$ is well above (below) the mountain crest height, it follows that the deformation of the pressure field by the mountain close to the ground has little impact on the torque.

The mean torques per season ( spring = March to May, etc.) and their standard deviations $\sigma_{i}$ as exerted by the Alps, the Atlas mountains and by Asia Minor are listed in Table I. The mean values are small for the Alps but may be as large as $\sim-2$ Hadley for the Atlas range in summer $\left(1\right.$ Hadley $\left.=10^{18} \mathrm{~J}\right)$. Recall that a mountain of $1000 \mathrm{~km}(200 \mathrm{~km})$ zonal (meridional) extent, and vertical side walls of $2000 \mathrm{~m}$ height induces a torque $T_{\lambda} \sim 8$ Hadley, if the meridional pressure difference across the mountain is $10 \mathrm{hPa}$ (Egger and Hoinka, 2006). Standard
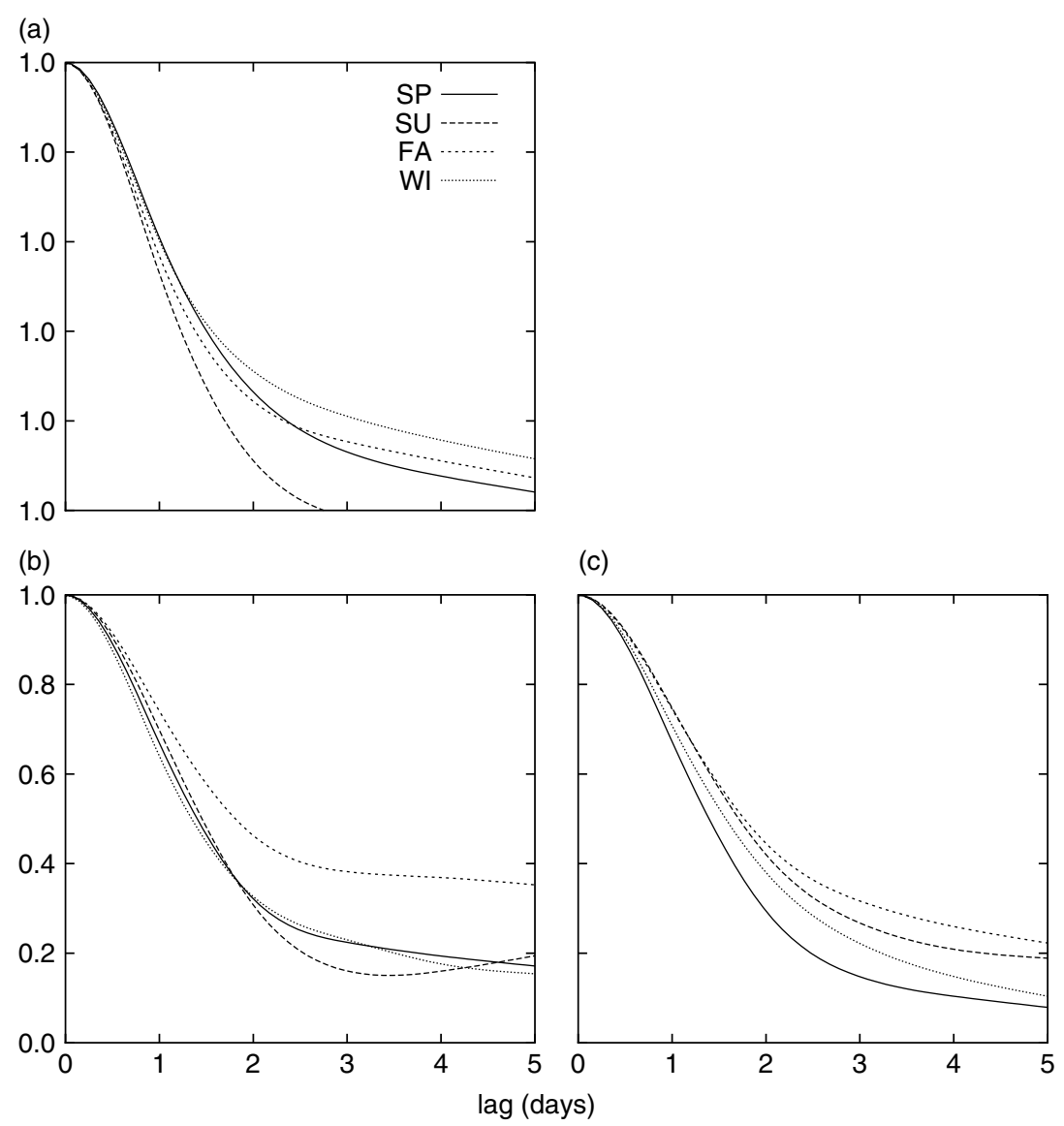

Figure 4. Autocorrelation of (a) $T_{\lambda \mathrm{AL}}$, (b) $T_{\lambda \mathrm{AT}}$, (c) $T_{\lambda \mathrm{AM}}$ as a function of lag $\tau$ (days) for $\mathrm{SP}=$ spring, $\mathrm{SU}=$ summer, $\mathrm{FA}=$ autumn, $\mathrm{WI}=$ winter. 
deviations in Table I are 0.6-2.2 Hadley, so that typical pressure differences across all three massifs are a few $\mathrm{hPa}$. The standard deviations of $T_{\lambda}$ are always larger than those of $T_{\varphi}$, but differences are small.

The autocorrelation of the zonal Alpine torque $T_{\lambda \mathrm{AL}}$ is displayed in Figure 4(a) for all seasons. The decay of the torque with increasing lag $\tau$ is rapid but there are also slow contributions in winter in particular. The decay of the autocorrelations of the meridional torques $T_{\varphi \mathrm{AL}}$ is similar to that of $T_{\lambda \mathrm{AL}}$, but the decay tends to be slightly slower except for summer (not shown). The decay of the $T_{\lambda \mathrm{AT}}$ autocorrelations is fairly slow with a value of 0.4 after 5 days in the autumn. The synoptic systems generating the Atlas torques must differ substantially from the Alpine ones. In contrast, $T_{\varphi \mathrm{AT}}$ events are relatively short-lived (not shown) while there appear to be low frequency contributions to $T_{\varphi \mathrm{AM}}$ in summer (Figure 4(c)).

The cross-correlation function of $T_{\lambda \mathrm{AL}}$ and $T_{\varphi \mathrm{AL}}$ as displayed in Figure 5(a) is positive for lags $|\tau| \leq$ 2 days. The correlation coefficient varies between 0.4 and 0.7. The curves are essentially symmetric with respect to $\tau=0$ but there appears to be a slight lead
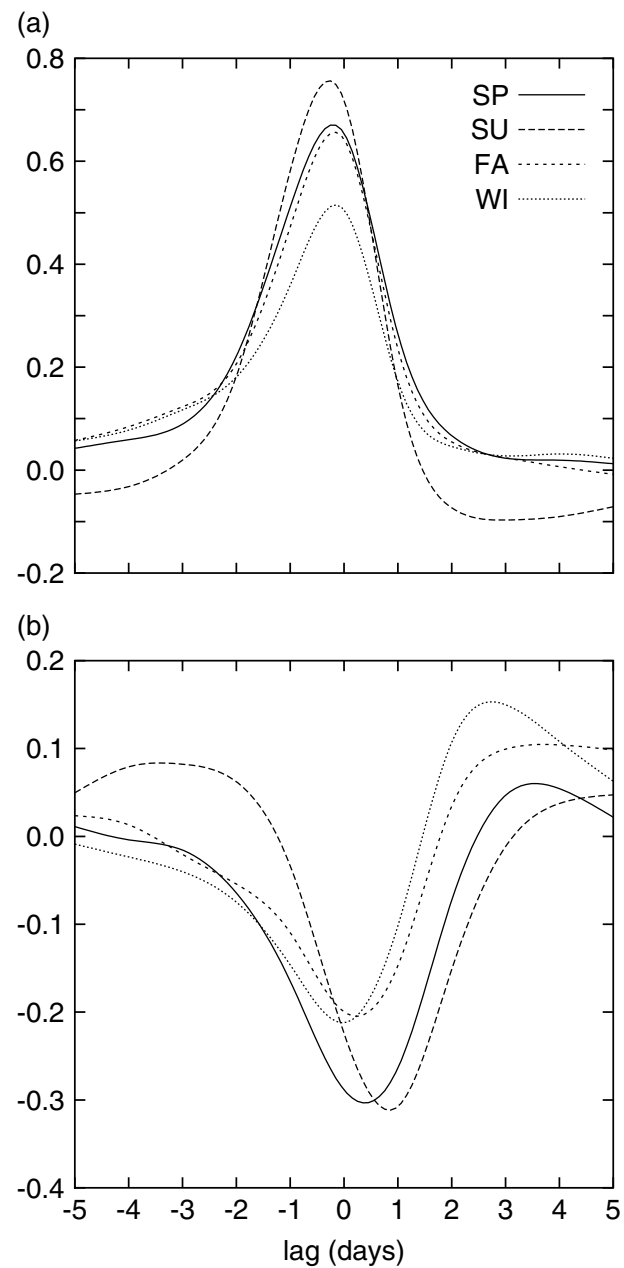

Figure 5. Cross-correlations of (a) $T_{\lambda \mathrm{AL}}$ and $T_{\varphi \mathrm{AL}}\left(T_{\lambda \mathrm{AL}}\right.$ leading) and (b) $T_{\lambda \mathrm{AL}}$ and $T_{\lambda \mathrm{AM}}\left(T_{\lambda \mathrm{AL}}\right.$ leading) as a function of lag $\tau$ (days) for the four seasons. of $T_{\varphi \mathrm{AL}}$. We have to wait for the presentation of the pressure fields to better understand Figure 5(a). Crosscorrelations between the torques at the three massifs have also been calculated. Such correlations must exist if the torques are mainly generated by eastward-moving large-scale waves. The most interesting result is presented in Figure 5(b). The cross-correlation of $T_{\lambda \mathrm{AL}}$ and $T_{\lambda \mathrm{AM}}$ attains a minimum of $\sim-0.2$ for lags $0<\tau \leq$ 1 day but reaches a positive maximum after two more days. The pressure systems which induce a torque at the Alps reach Asia Minor 2-3 days later (see also Figure 6).

(a)

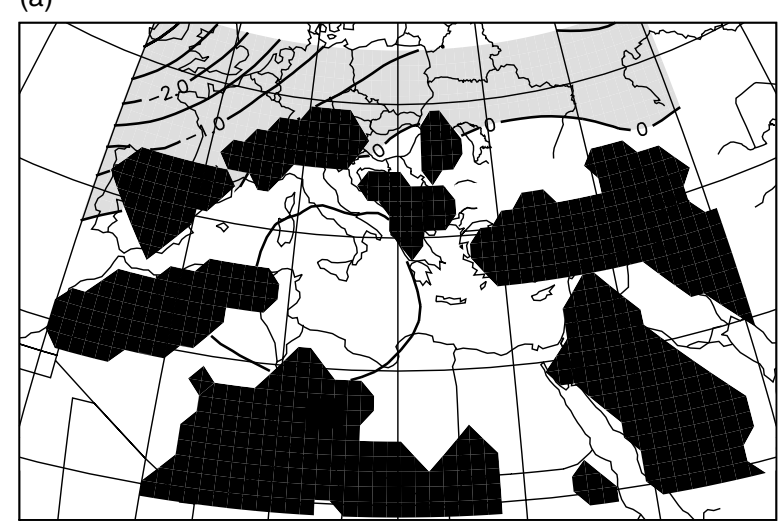

(b)

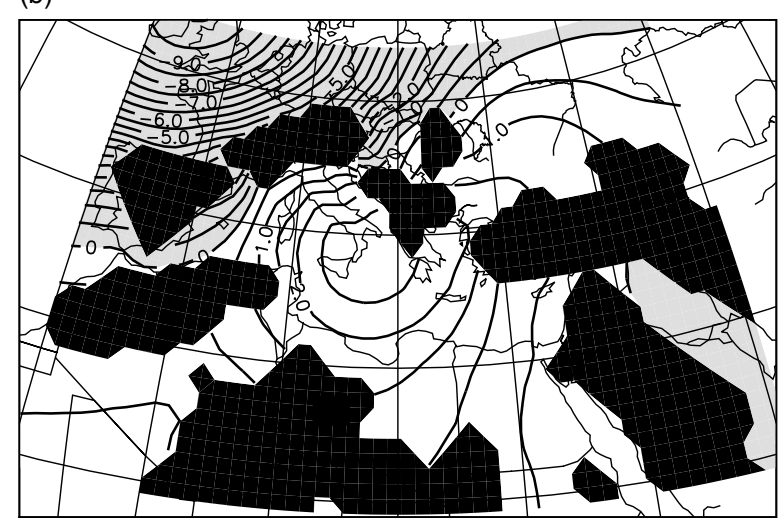

(c)

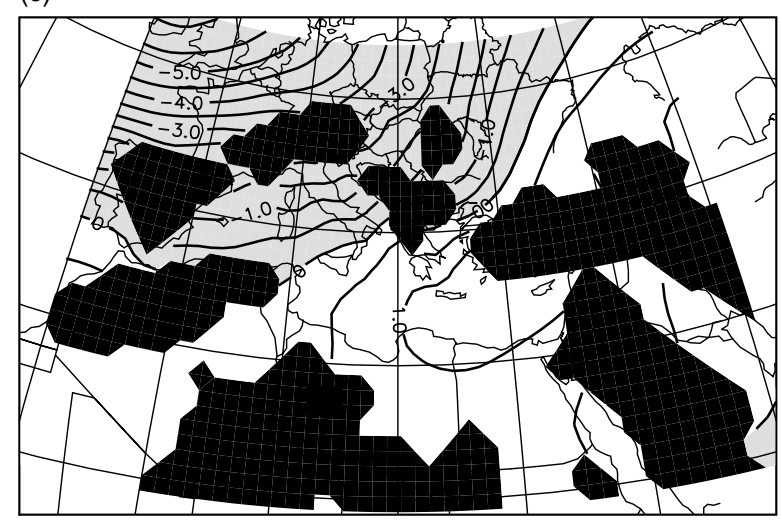

Figure 6. Covariance $C\left(T_{\lambda \mathrm{AL}}, p \mid \tau\right)$ of the zonal Alpine torque with pressure (hPa) in winter at $z=500 \mathrm{~m}$ for (a) lag $\tau=-4$, (b) $\tau=0$, and (c) $\tau=2$ days. The contour interval is $0.5 \mathrm{hPa}$, with grey shading denoting negative values. Dark shading is topography $>500 \mathrm{~m}$. 
(a)

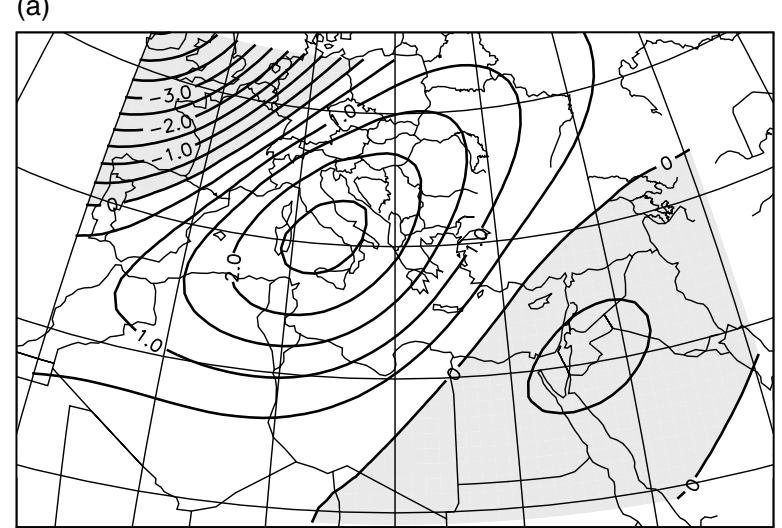

(b)

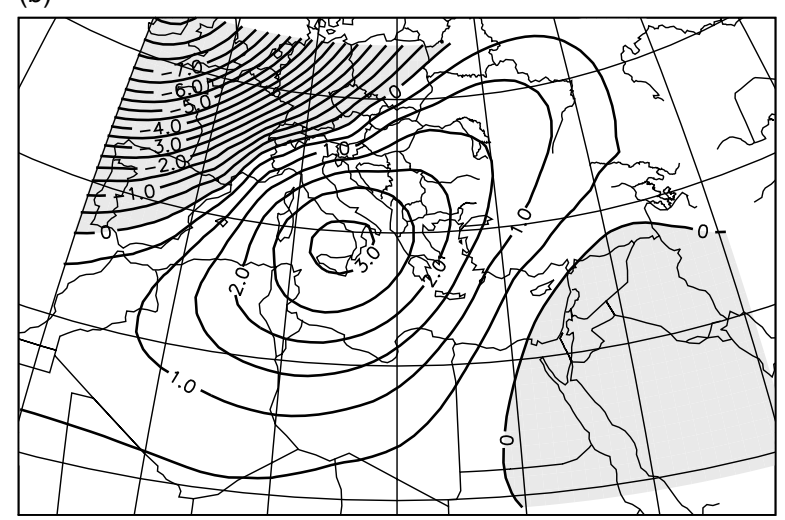

(c)

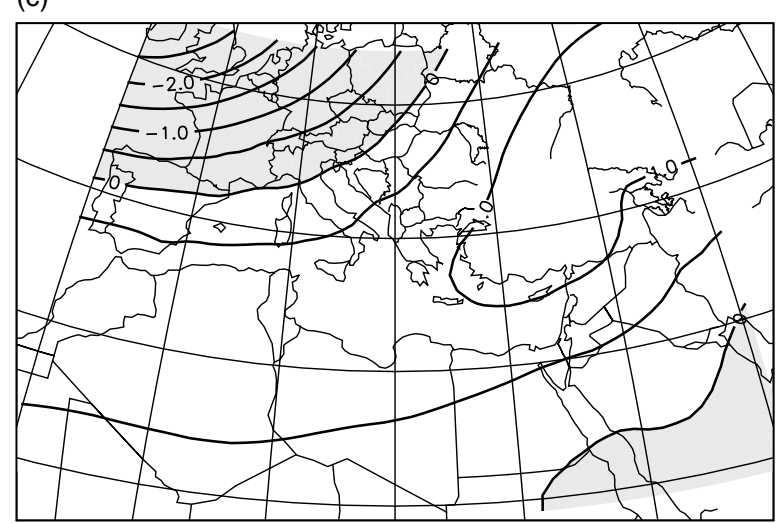

Figure 7. Covariance $C\left(T_{\lambda \mathrm{AL}}, p \mid \tau\right)$ of $T_{\lambda \mathrm{AL}}$ with pressure in winter for (a) $\tau=0, z=9500 \mathrm{~m}$; (b) $\tau=0 ; \mathrm{z}=2500 \mathrm{~m}$; (c) $\tau=4$ days, $\mathrm{z}=2500 \mathrm{~m}$. The contour interval and shading are as Figure 6 .

\section{Torque events}

\subsection{Alpine zonal torques $T_{\lambda \mathrm{AL}}$}

We concentrate on events in winter when the standard deviations are largest. Surface pressure anomalies are negative above the Atlantic and north of the Alps at $\tau=-4$ days (Figure 6(a)) while high pressure covers the Mediterranean with a maximum south of the Alps. Amplitudes grow considerably during the next four days (Figure 6(b)). The Atlantic low moves slowly towards the east with minimum pressure $<-9 \mathrm{hPa}$. There is continuous pressure rise south of the Alps with a closed $2.5 \mathrm{hPa}$ isobar in Southern Italy at $\tau=0$ (Figure 6(b)) but there is little movement of the high. The Alps appear to distort the surface pressure distribution at least near $\tau=0$ with pressure rise (fall) in the southwest (northeast) in agreement with Figure 2(a). Pressure rise in the lee is over at $\tau=0$. From then on, the anticyclone begins to move eastward and to decrease in amplitude. There is a closed $1 \mathrm{hPa}$ contour near Turkey at $\tau=$ 2 days (Figure 6(c)). Negative pressure anomalies fill the northwestern Mediterranean. The low is completely dissolved at $\tau=5$ days (not shown).

Higher up $(z=2500 \mathrm{~m}$; Figure 7(b,c)), the situation is fairly similar to that near the bottom. There is a slowly eastward-moving trough above the Atlantic and France while a ridge above the western Mediterranean stays in place for $\tau \leq 0$. At $\tau=0$, the centre of the ridge with maximum pressure of $3 \mathrm{hPa}$ is located almost exactly above the surface centre with its $2.5 \mathrm{hPa}$ maximum. The layer below crest height must be relatively warm so that the surface pressure anomaly is smaller than that at crest height. The tilt of the isobars at $z=2500 \mathrm{~m}$ agrees quite well with that in Figure 2(a). Even the deformation of the pressure field as anticipated in Figure 2(a) can be seen in Figures 6(b) and 7(b).

The ridge is found even close to the tropopause (Figure $7(\mathrm{a}) ; z=9.5 \mathrm{~km}$ ). The amplitudes of the anomalies are slightly smaller than at $z=2500 \mathrm{~m}$ and there is a closed $2.5 \mathrm{hPa}$ isobar. Thus the large-scale pressure system is fairly deep and does not exhibit a tilt of the vertical axis at $\tau=0$. The trough is then moving slowly eastward and its meridional tilt becomes more pronounced with increasing lag (Figure 7(c)).

The Mediterranean area is anomalously warm at $\tau=0$ with a minimum above the Alpine upslope (Figure 8). This minimum implies a hydrostatic enhancement of the torque due to the impact of the Alps. The horizontal winds near the surface at $\tau=0$ appear to split south of the Alps with a merging of both branches to the north (Figure 9). There is substantial flow across the Alps at the next levels (not shown). Thus the torque indeed reduces the angular moment of the cross-Alpine flow.

The torque contributions $Q_{\lambda}\left(z_{\mathrm{o}}\right)$ (3.2) for the zonal torque events $T_{\lambda \mathrm{AL}}$ are displayed in Figure 10. The contributions are maximal at $z_{0}=1.5 \mathrm{~km}$ except for $\tau=2$ days. The decrease below this height is an artefact as discussed above. The variation of $Q_{\lambda}$ with $z_{\mathrm{o}}$ is, of course, due to the temperature anomalies above the slopes. There is a clear message in Figure 10: the effect of the Alps on the temperature below, say, $z_{\mathrm{o}}=$ $4000 \mathrm{~km}$ is quite strong for $\tau=-1$ and $\tau=0$ when a substantial fraction of the torque results from these low-level temperature anomalies (also Figure 8). There is, however, hardly any such effect at $\tau=1$ and the lowlevel temperature field even reduces the torque at $\tau=$ 2 days. In contrast, the relative contribution by the upper layers due to the large-scale pressure field grows from $\tau=-1$ to become completely dominant at $\tau=2$ days. Note, that the standard deviation of $T_{\lambda \mathrm{AL}}$ is 1.5 Hadley in winter, in good agreement with Figure 10. All in all, Figure 10 supports the simple scheme to separate the 


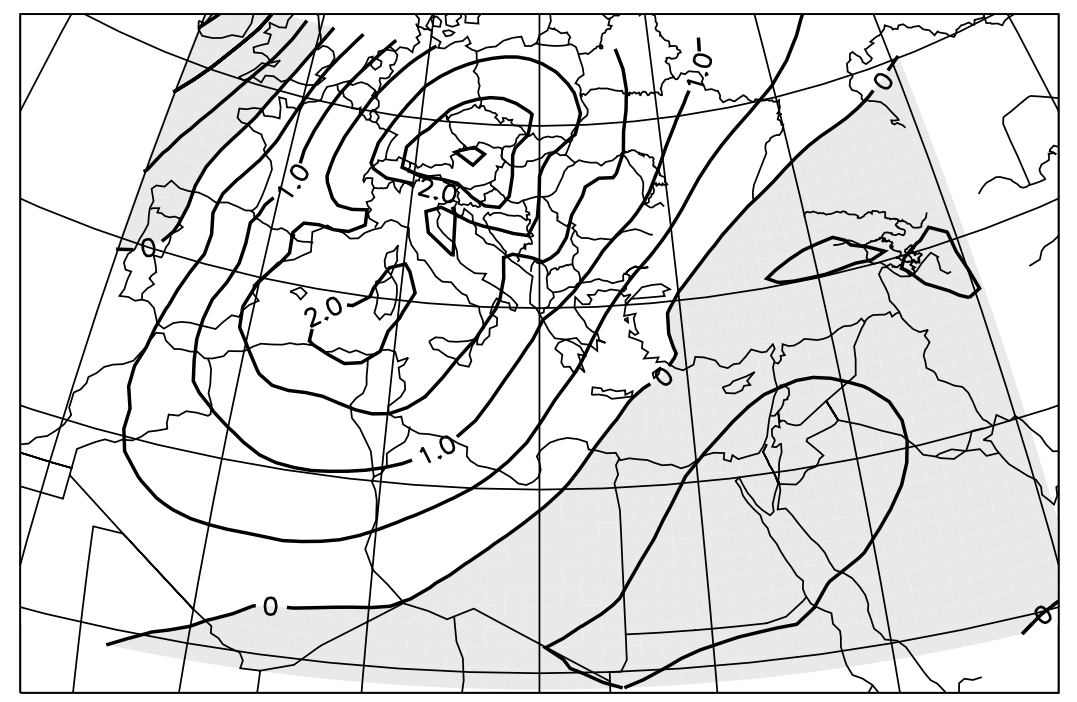

Figure 8. Covariance $C\left(T_{\lambda \mathrm{AL}}, \theta \mid \tau\right)$ of $T_{\lambda \mathrm{AL}}$ with potential temperature $(\mathrm{K})$ in winter at $\tau=0, \mathrm{z}=2500 \mathrm{~m}$. Negative values are shaded, and the contour interval is $0.5 \mathrm{~K}$.

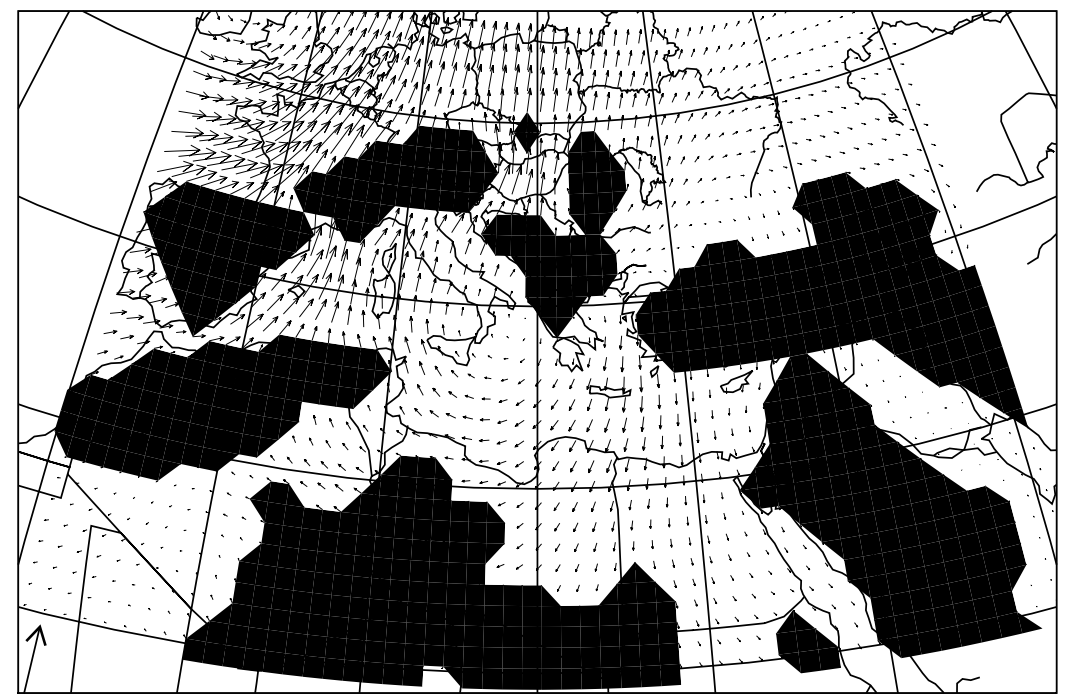

Figure 9. Covariance $C\left(T_{\lambda \mathrm{AL}}, \mathbf{v} \mid \tau\right)$ of $T_{\lambda \mathrm{AL}}$ with the horizontal wind in winter at $z=500 \mathrm{~m}$ for $\tau=0$. The arrow in the lower left corner represents a velocity of $10 \mathrm{~m} \mathrm{~s}^{-1}$. Dark shading is topography $>500 \mathrm{~m}$.

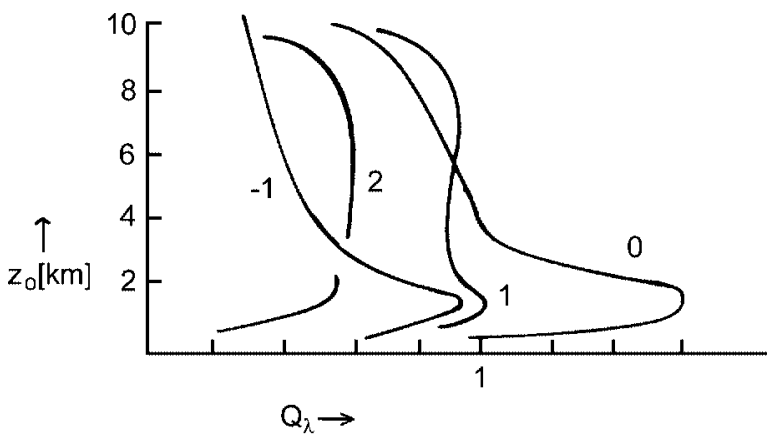

Figure 10. Torque covariance $Q_{\lambda}\left(z_{\mathrm{o}}\right)$ (Hadley) for the torque event $T_{\lambda \mathrm{AL}}$ in winter giving the contribution (from (3.2)) of all layers above the height $z_{\mathrm{o}}$ to the total torque covariance. The lag (days) is given by the number on each curve.

contribution of large-scale field and low-level flow as illustrated in Figure 2.
Precipitation anomalies (Figure 11) are positive in the southwesterly flow ahead of the trough and negative in the ridge domain as one might expect. Obviously, precipitation acts to reduce the torque.

The sequence of events in summer differs somewhat from that in winter. There are almost no surface perturbations in the Mediterranean for $\tau \leq-3$ days. A low enters the analysis domain from the northwest during $T_{\lambda \mathrm{AL}}$ events while a weak anticyclone develops south of the Alps (Figure 12) which moves eastward later. Amplitudes are smaller than in winter. The distortion of the surface pressure field near the Alps is broadly consistent with Figure 2(a) given the fact that the large-scale flow is southwesterly above the Alps at that time (not shown). This flow is due to a deep high extending up to the troposphere which enters the analysis domain at $\tau \sim-2$ days northwest of the Alps to be above this massif near $\tau=0$. Of course, this type of flow evolution is 


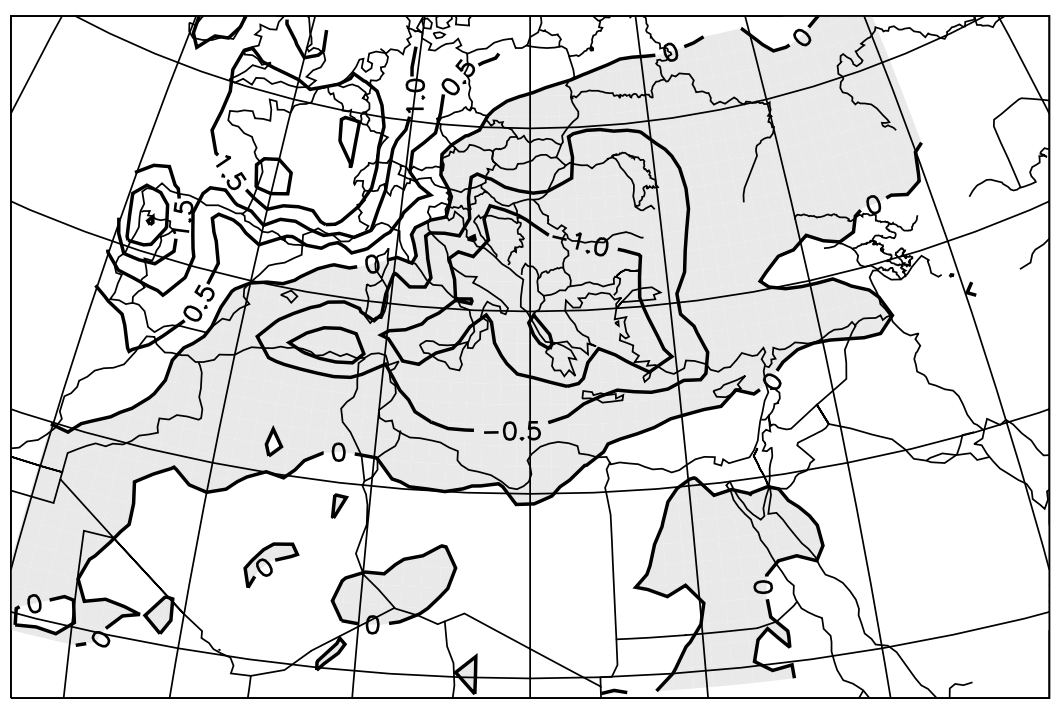

Figure 11. Covariance $C\left(T_{\lambda \mathrm{AL}}, R \mid \tau\right)$ of $T_{\lambda \mathrm{AL}}$ with precipitation $\left(\mathrm{mm} \mathrm{day}^{-1}\right.$ ) in winter for $\tau=0$. The contour interval is $0.5 \mathrm{~mm}$ day ${ }^{-1}$, and negative values are shaded.

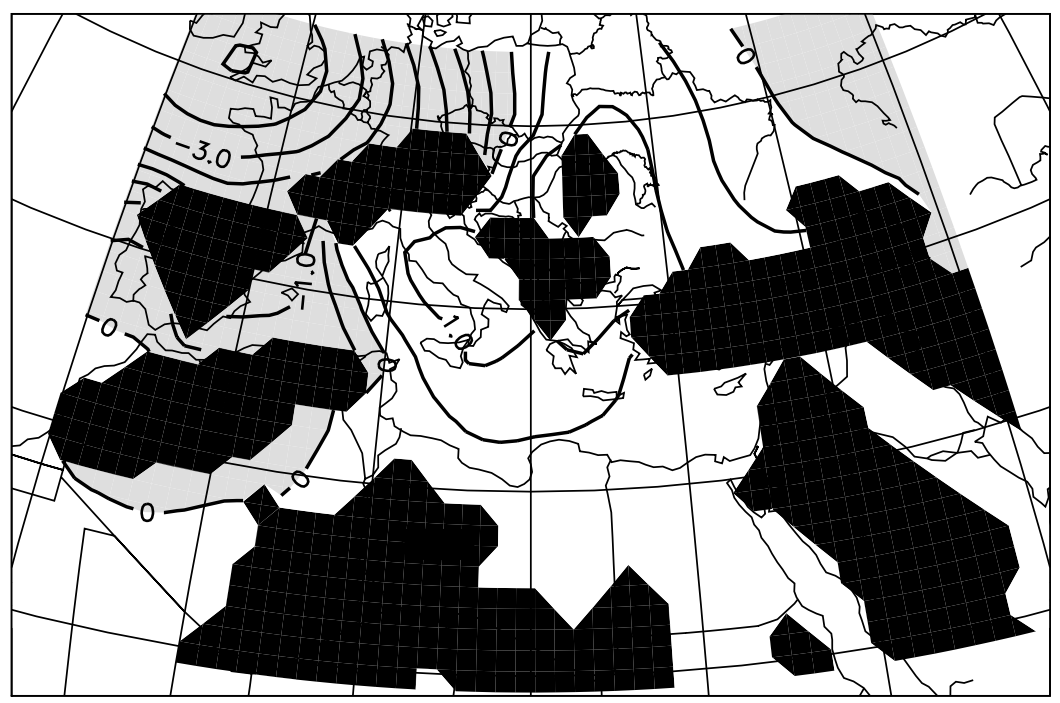

Figure 12. Covariance $C\left(T_{\lambda \mathrm{AL}}, p \mid \tau\right)$ of pressure at $\mathrm{z}=500 \mathrm{~m}$ with $T_{\lambda \mathrm{AL}}$ at $\tau=0 \mathrm{in} \mathrm{hPa}$ in summer. The contour interval and shading are as Figure 6.

quite reminiscent of the winter cases. The curves $Q_{\varphi}\left(z_{0}\right)$ show a relatively weak impact of the large-scale field for $\tau<0$, which however becomes quite important for positive lags similar to Figure 10.

\section{2. $\quad$ Alpine meridional torques $T_{\varphi \mathrm{AL}}$}

The winter case $T_{\varphi \mathrm{AL}}$ is discussed here in detail for comparison with the $T_{\lambda \mathrm{AL}}$ event. The near-surface pressure distribution at $\tau=-4$ days indicates that a low is located in the Atlantic while a ridge is found north of the Alps (Figure 13(a)). Thus, the pressure pattern in Figure 13(a) differs profoundly from that in Figure 6(a). In particular, the isobars near the Alps are tilted from northwest to southeast. The ridge intensifies and protrudes southeastward into the Mediterranean with increasing lag (Figure 13(b)). This leads to a fairly strong zonal pressure gradient in the Alpine domain as one would expect for a $T_{\varphi \mathrm{AL}}$ event. The Alps distort the pressure and induce relatively low pressure northeast of the Alps and high pressure in the south. At $\tau=2$ days, there is little north-south asymmetry of the surface pressure distribution at the Alps (Figure 13(c)). The trough is then moving eastward and its centre is seen north of the Black Sea at $\tau \sim 4-5$ days. The ridge at $z=2500 \mathrm{~m}, \tau=0$ (Figure 13(d)) is fairly similar to that at the ground but the deformation of the isobars is less pronounced. The orientation of the isobars above the Alps at $\tau=0$ has a similar tilt to that predicted by Figure 2(b). The deformation of the isobars at the Alps also fits Figure 2(b) 
(a)

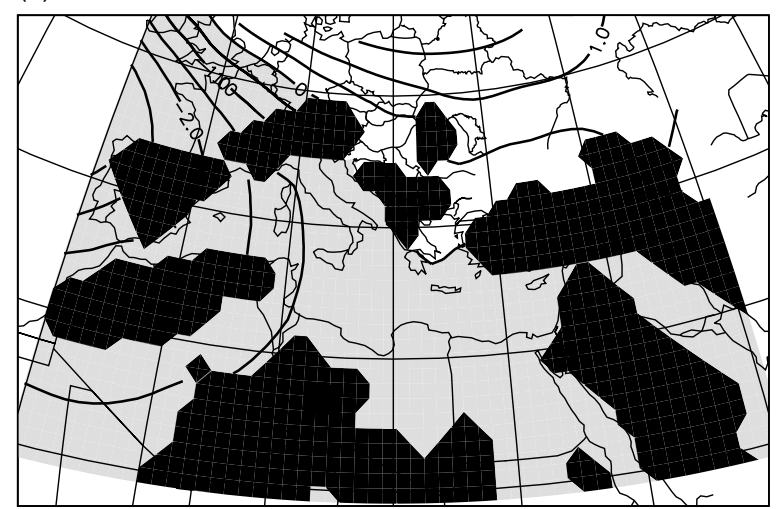

(c)

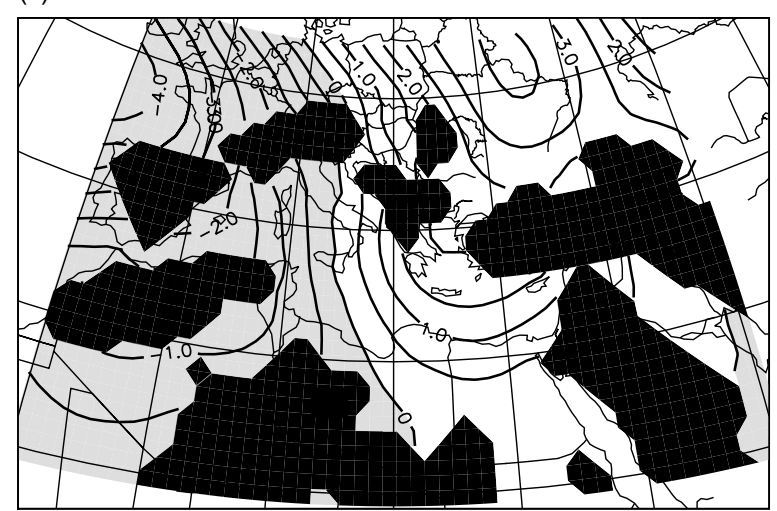

(b)

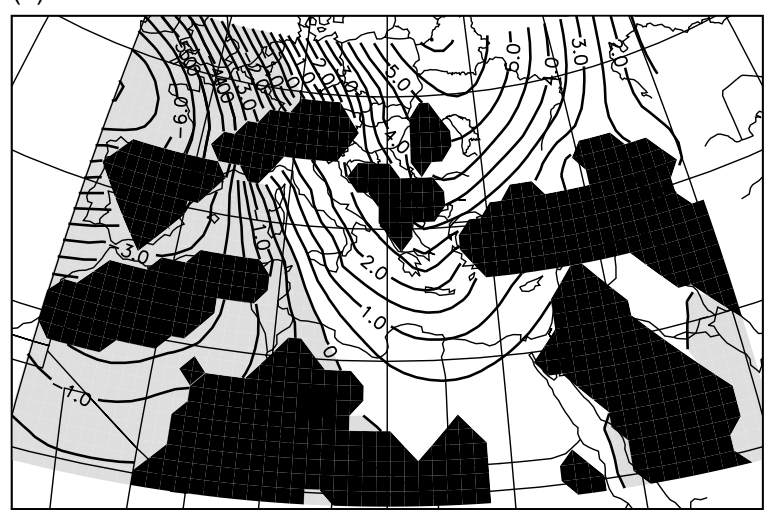

(d)

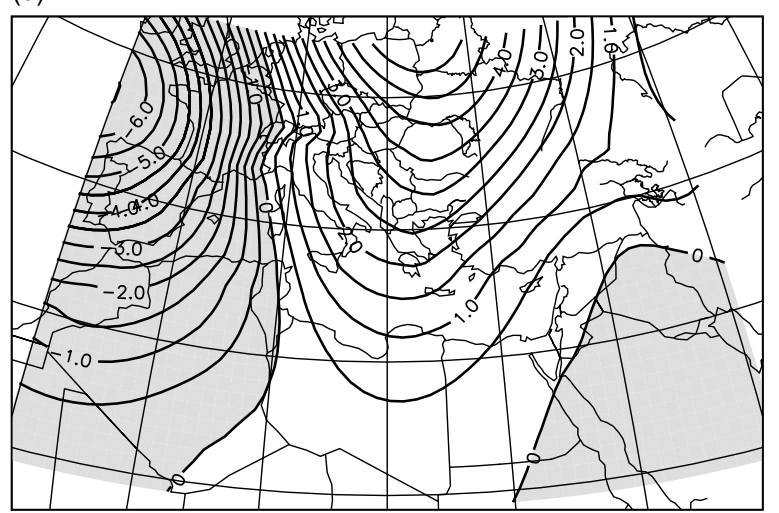

Figure 13. Covariance $C\left(T_{\varphi \mathrm{AL}}, p \mid \tau\right)(\mathrm{hPa})$ in winter at (a) $\tau=-4$ days, $\mathrm{z}=500 \mathrm{~m}$, (b) $\tau=0, \mathrm{z}=500 \mathrm{~m}$, (c) $\tau=2$ days, $\mathrm{z}=500 \mathrm{~m}$; (d) $\tau=0$, $\mathrm{z}=2500 \mathrm{~m}$. The contour interval and shading are as Figure 6 .

quite well. Both the high and low at the surface in Figures $13(a, b, c)$ are linked to deep waves extending at least to the tropopause (not shown).

The profiles of $Q_{\varphi}\left(z_{0}\right)$ (Figure 14) are similar to those in Figure 10 except that the low-level maxima are less pronounced. The low-level deformation again contributes significantly to the torque at $\tau=-1$ day, but less so at $\tau=0$ where the deep large-scale contribution is already dominant. The impact of the Alps even reduces the torque for $\tau>0$ when the contribution by the layers above $z_{\mathrm{o}} \sim 6 \mathrm{~km}$ is larger than, say, that at $z_{\mathrm{o}}=2.5 \mathrm{~km}$. The positive correlation of $T_{\lambda \mathrm{AL}}$ and $T_{\varphi \mathrm{AL}}$ (Figure 5) is illustrated nicely by Figure 13(a-c). In all situations the surface pressure in the south is higher than in the north so that $T_{\lambda \mathrm{AL}}>0$.

The ridge is bringing warm air in its rear into the Mediterranean which fills the western Mediterranean at $\tau=1$ day (not shown). Higher up, the cool anomalies stay in the northern part of the Mediterranean. Rainfall is strong east of the Alps and a minimum is found in the lee. The sequence of events in summer is broadly similar to that in winter and is, therefore, not shown. The profiles $Q_{\varphi}\left(z_{0}\right)$ in summer deviate from those in Figure 14 because the contribution by the large-scale field is negative (albeit weak) for $-4 \leq \tau \leq-1$. For $\tau>0$ it is the contribution by the upper levels which dominates as in Figure 14.

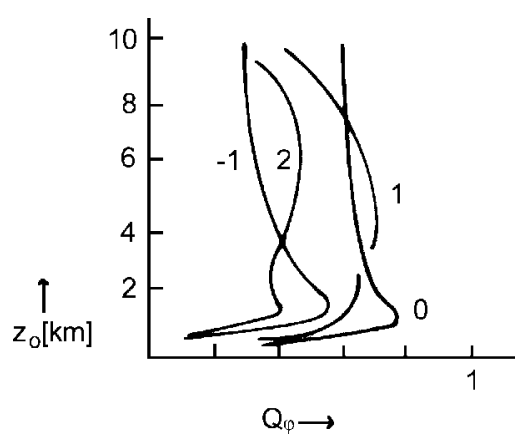

Figure 14. Torque covariance $Q_{\varphi}\left(z_{0}\right)$ (3.2) (Hadley) for the torque event $T_{\varphi \mathrm{AL}}$ in winter giving the contribution of all layers above height $z_{\mathrm{o}}$ to the 'torque' (from (3.1)). The lag (days) is given by the number on each curve.

\subsection{Atlas zonal torques $T_{\lambda \mathrm{AT}}$}

A winter event begins with a low pressure system out in the Atlantic which moves towards the Mediterranean where pressure is falling slowly with increasing lag (Figure 15). The low-level pressure field at $\tau=0$ (Figure 15(b)) is dominated by this low which obviously exerts a positive torque $T_{\lambda \mathrm{AT}}$ at the Atlas mountains with a positive surface pressure anomaly over the Sahara. There is no obvious distortion of the surface pressure field by the Atlas mountains. Two days later, the surface pressure anomalies are negative south of the Atlas 
(a)

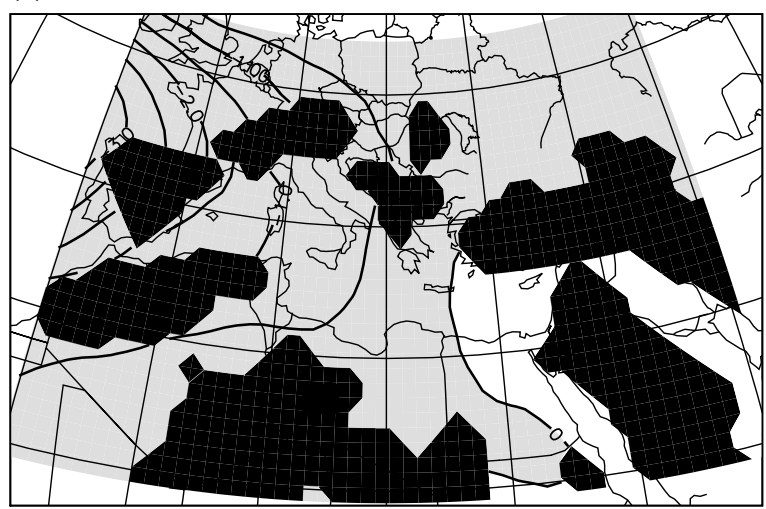

(c)

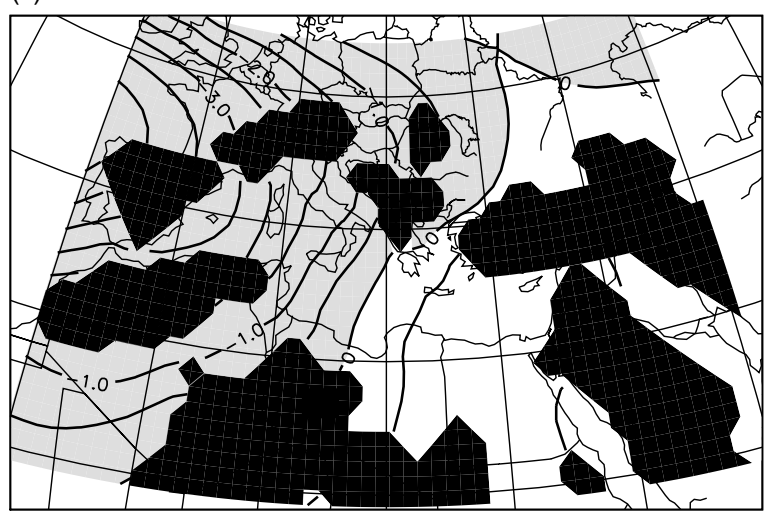

(b)

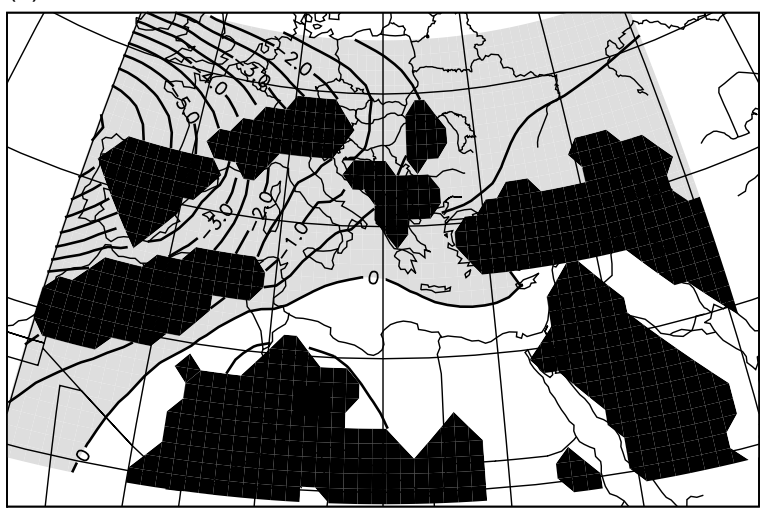

(d)

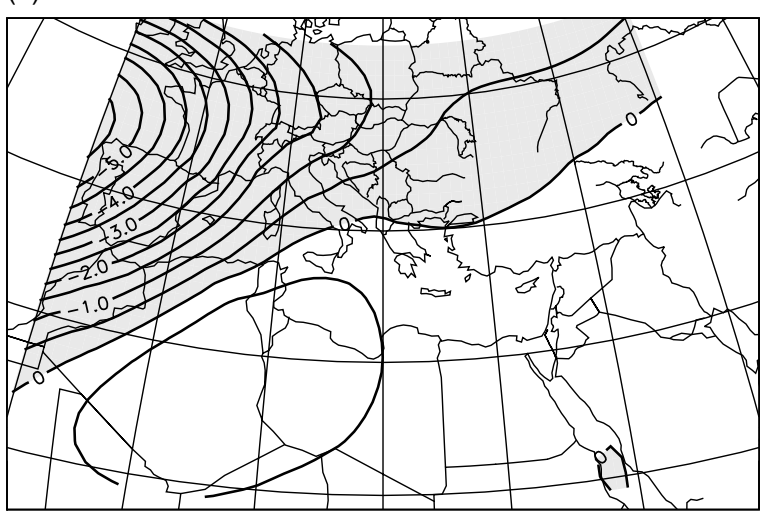

Figure 15. Covariance $C\left(T_{\lambda \mathrm{AL}}, p \mid \tau\right)(\mathrm{hPa})$ in winter at (a) $\tau=-2$ days, $\mathrm{z}=500 \mathrm{~m}$, (b) $\tau=0, \mathrm{z}=500 \mathrm{~m}$, (c) $\tau=2$ days, $\mathrm{z}=500 \mathrm{~m}$, (d) $\tau=0$, $\mathrm{z}=2500 \mathrm{~m}$. The contour interval and shading are as Figure 6 .

range but the Atlantic low has hardly moved. The pressure anomalies at $z=2500 \mathrm{~m}$ (Figure 15(d)) show, of course, fairly similar features except that the high above the Sahara at $\tau=0$ is more pronounced and can be easily detected even at $\tau=5$ days (not shown). There is little if any impact of the Atlas massif on the pressure distribution. The meridional tilt of the isobars in the Atlas region (Figure $15(\mathrm{~d})$ ) is from southwest to northeast in agreement with Figure 2(a). The pressure field at $z=9500 \mathrm{~m}$ (not shown) shows a meridionally tilted high above Africa which is even stronger than that at $z=2500 \mathrm{~m}$.

The dominance of upper-level flow is documented quite clearly in Figure 16 where $Q_{\lambda}\left(z_{\mathrm{o}}\right)$ decreases only slowly with height for $\tau=-1$ and $\tau=0$ and where there is no pronounced maximum of $Q_{\lambda}$ near the ground. The contribution by the lower levels is negative for $\tau>0$. The southeasterlies ahead of the low bring warm air to the Atlas region (Figure 17). They are directed almost parallel to the Atlas range so that there is relatively little flow over the massif. Correspondingly there is little if any flow deformation near the Atlas range. The situation at $\tau=0$ is exceptional (Figure 17; also Figure 15(b)) with strong flows across the Atlas mountains and vigorous southerlies in the western Mediterranean. Moist air is flowing into the Mediterranean and weak anomalies of precipitation are found in southern France and northern Italy (not shown).

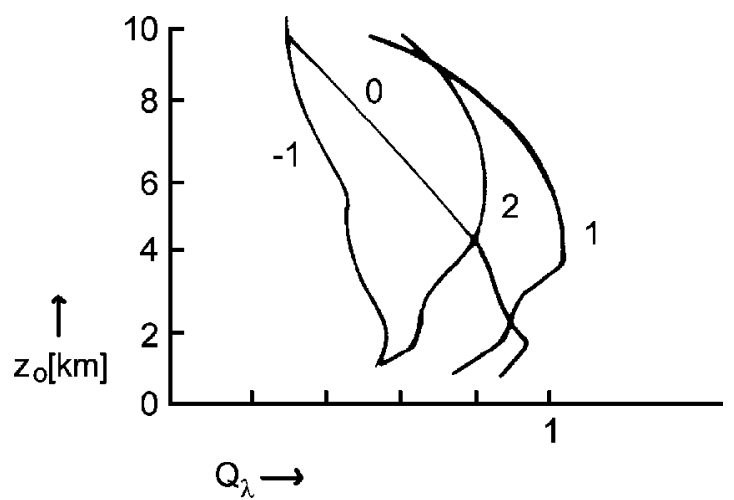

Figure 16. Torque contribution $Q_{\lambda}\left(z_{0}\right)$ (Hadley) in winter for torque events $T_{\lambda \text { AT }}$. The lag (days) is given by the number on each curve.

\subsection{Atlas meridional torques $T_{\varphi \mathrm{AT}}$}

The surface pressure distribution in the meridional Atlas cases is dominated by a high which moves across the Alps at $\tau \sim-2$ days (Figure 18(a)) and attains a maximum strength south of the Alps at $\tau=0$ (Figure 18(b)). The further eastward motion of this anticylone is quite slow. The large-scale pressure distribution fits Figure 2(b) quite well (Figure 18(c)). The contribution of the lowest layers to the mountain torque is, however, quite small. For example (Figure 19), the profile $Q_{\varphi}\left(z_{\mathrm{o}}\right)$ at $\tau=0$ depends 


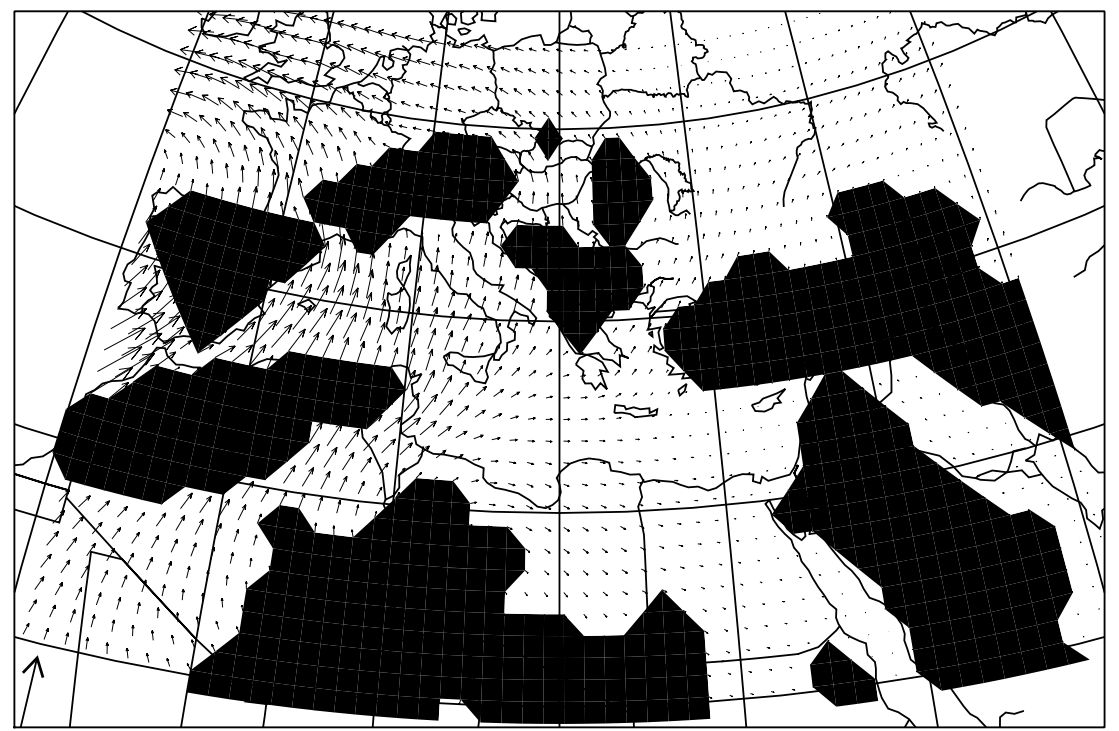

Figure 17. Covariance $C\left(T_{\lambda \mathrm{AT}}, \mathbf{v} \mid \tau\right)$ in winter at $\mathrm{z}=500 \mathrm{~m}, \tau=0$. The arrow in the lower left corner represents a velocity of $5 \mathrm{~m} \mathrm{~s}^{-1}$.

(a)

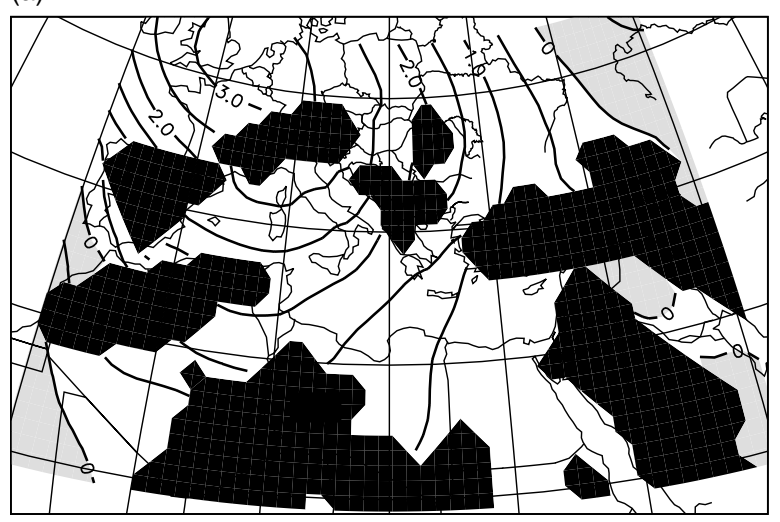

(b)

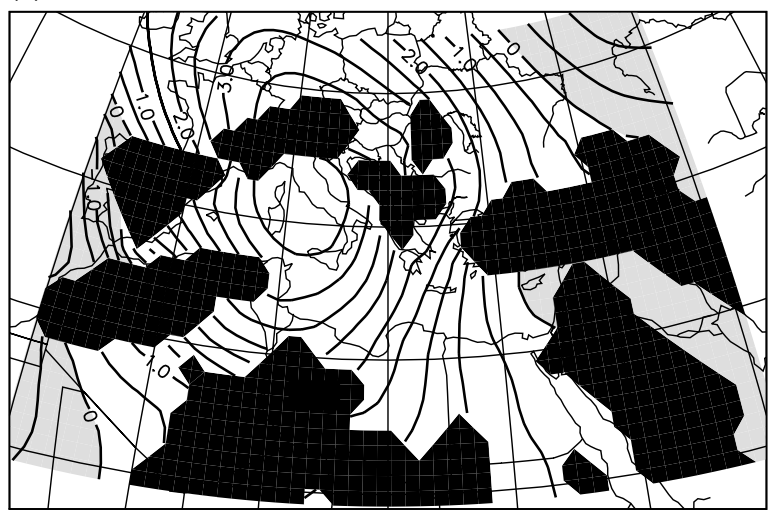

(c)

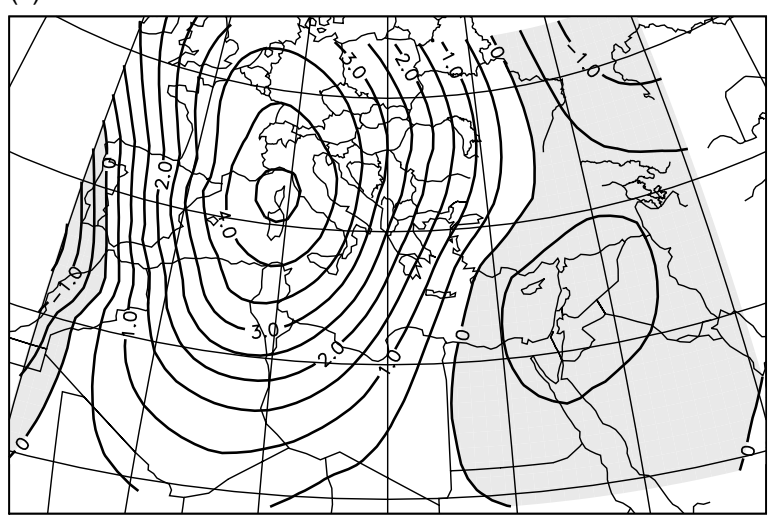

Figure 18. Covariance $C\left(T_{\varphi \mathrm{AT}}, p \mid \tau\right)(\mathrm{hPa})$ in winter at (a) $\tau=-2$ days; $z=500 \mathrm{~m}$; (b) $\tau=0, z=500 \mathrm{~m}$; (c) $\tau=0, z=2500 \mathrm{~m}$. The contour interval and shading are as Figure 6.

hardly on $z_{0}$. The contribution by the lower layer is negative for $\tau>0$ just as in the zonal case.

\subsection{Asia Minor zonal torque $T_{\lambda \mathrm{AM}}$}

The location of Turkey in the eastern part of the analysis domain requires strong synoptic systems covering the
Mediterranean to induce substantial torque events. We concentrate again on winter where the standard deviation of the torque is largest. A wide low pressure system with its centre in the Baltic Sea begins to interact with the massifs of Asia Minor at $\tau \sim-2$ days (Figure 20(a)). As is typical of $\mathrm{T}_{\lambda}$ events, southwesterlies blow towards the mountain range (Figure 21). The 
related low-level pressure distribution with a high in the south and low pressure extending along the Black Sea coast of Turkey (Figure 20(b)) corresponds with expectations (Figure 2(a)). The inspection of the pressure maps at $z=9500 \mathrm{~m}$ (Figure 20(d)) shows that this high is quite strong and pronounced at upper levels. Note the northwestward tilt of the trough's axis. Thus we have again a case where the large-scale field at upper levels contributes significantly to the torque. This conclusion is corroborated by the profiles of $Q_{\lambda}\left(z_{\mathrm{o}}\right)$ which show clearly the strong contribution of the large-scale flows to the torque (Figure 22) but the low-level contribution is quite important for all lags shown. The bulges related to the low-level maxima extend up to height of $\sim 3000 \mathrm{~m}$. Warm air is filling the Mediterranean at low levels ahead of the trough (not shown). Nevertheless, the temperature anomalies north of Asia Minor are larger than in the south and, therefore, the low-level pressure field contributes significantly to the torque as can be seen also from Figure 20.

The near-surface winds entering the Black Sea from the south are quite strong at $\tau=0$ (Figure 21). Note the anticyclonic circulation in the Levant. Correspondingly, orographic precipitation is strong in this south-tosouthwesterly flow (Figure 23).

The situation in summer is surprisingly similar to that in winter with a wide trough moving towards and over

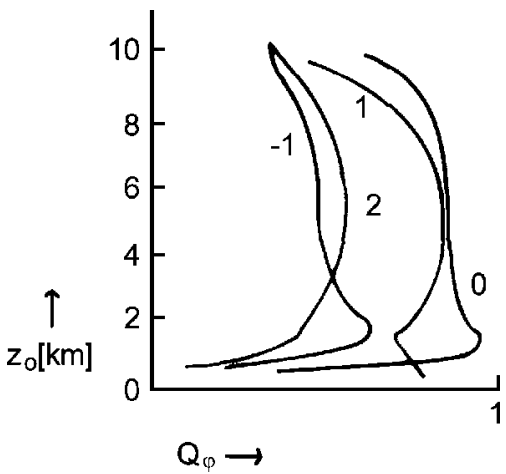

Figure 19. $Q_{\varphi}\left(z_{\mathrm{o}}\right)$ in winter (Hadley) for torque events $T_{\varphi \mathrm{AT}}$. The lag (days) is given by the number on each curve.

Asia Minor (not shown). As in winter, there is a strong impact of the lowest layers on the torque even for positive torques.

\section{Discussion and conclusions}

The simple scheme in Figure 2 has been proposed in order to explain the basic features of mountain torque events in the Mediterranean where the selected mountain massifs have a zonal extent of $\leq 1000 \mathrm{~km}$ and a width of a few hundred $\mathrm{km}$. It is assumed in Figure 2 that

(b)

(a)

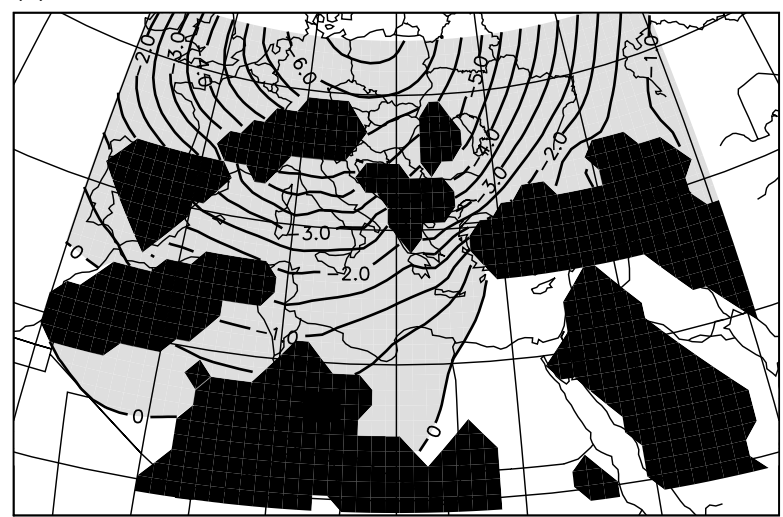

(c)

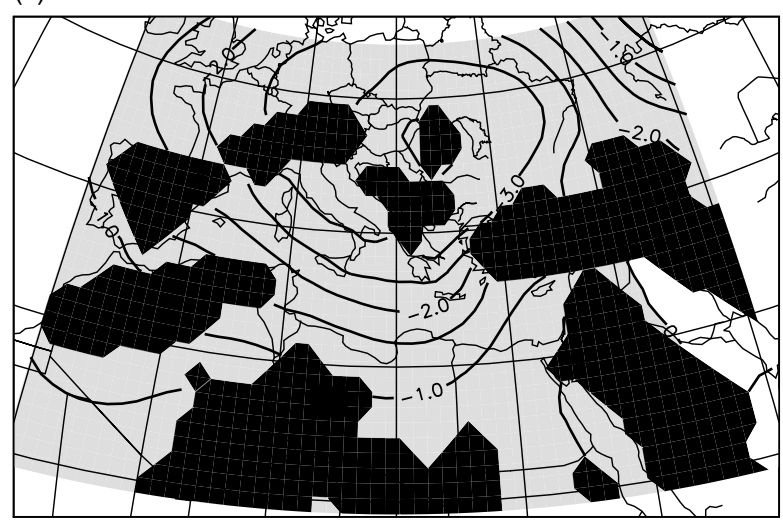

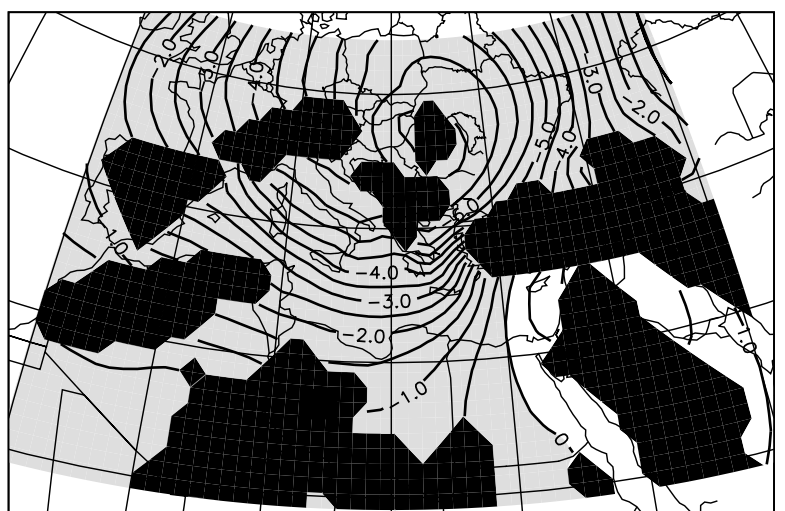

(d)

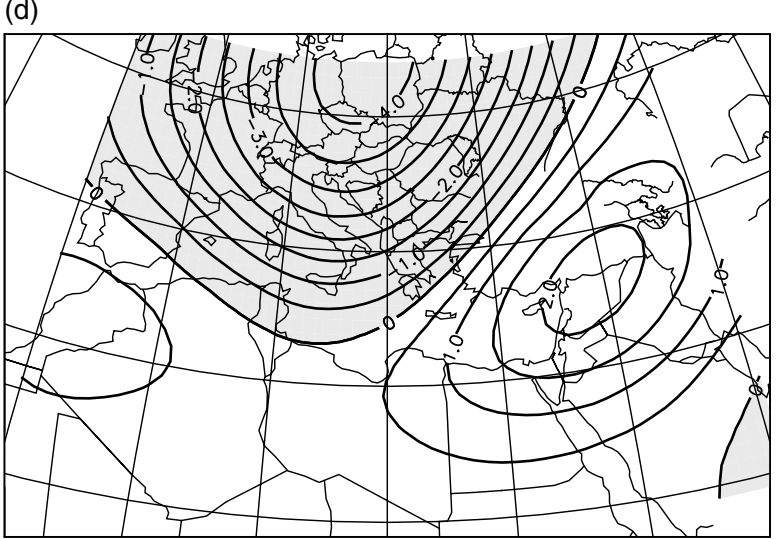

Figure 20. Covariance $C\left(T_{\lambda \mathrm{AM}}, p \mid \tau\right)$ (hPa) in winter at (a) $\tau=-2$ days; $z=500 \mathrm{~m}$; (b) $\tau=0, z=500 \mathrm{~m}$, (c) $\tau=2$ days, $z=500 \mathrm{~m}$, (d) $\tau=0, z=9500 \mathrm{~m}$. The contour interval and shading are as Figure 6 . 


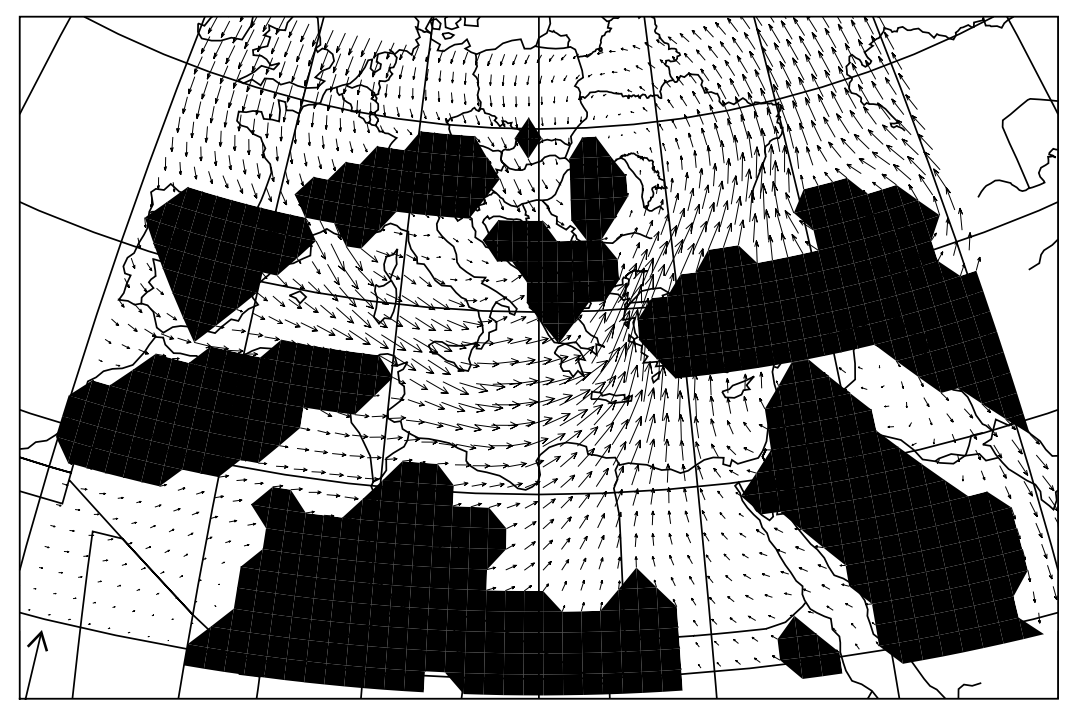

Figure 21. Covariance $C\left(T_{\lambda \mathrm{AM}}, \mathbf{v} \mid \tau\right)$ of $T_{\lambda \mathrm{AM}}$ with the horizontal wind velocity in winter at $z=500 \mathrm{~m}(\tau=0)$. The arrow in the lower left corner represents a velocity of $10 \mathrm{~m} \mathrm{~s}^{-1}$.

the scale of the systems entering the Mediterranean is larger than that of the massifs. By and large this assumption is corroborated by the observations. The lowlevel perturbations of the surface pressure caused by the mountains are assessed following the rule that the torques exerted by the mountains reduce the angular momentum of the air flow impinging on them. This scheme turned out to be quite successful. The tilt of the isobars of the large-scale systems is invariably from southwest to northeast for $T_{\lambda}$ events and from northwest to southeast for $T_{\varphi}$ torques. The low-level perturbations indeed follow the simple rule of an upstream ridge and a downstream depression. These deformations do not extend over heights of more than $4 \mathrm{~km}$. This can be seen from the pressure maps but also from the $Q$ curves. The contribution by the lower layers is sometimes quite pronounced, but its amplitude becomes quite small with increasing $z_{0}$. It is difficult to assign a horizontal scale to these orographic perturbations. For example, the wind fields in Figure 9 may suggest a moderately large Alpine influence while the signals in Figure 8 are fairly confined to the Alpine domain. The results for the Atlas range are exceptional insofar as the low-level contribution to the surface pressure pattern is hardly visible (except perhaps at $\tau=0$ ). The positive contribution to the torque by the lowest layers is strong for $\tau \leq 0$ in the Alpine case and also for positive lags in Asia Minor. These conclusions apply to both types of torque.

It is a somewhat surprising feature of our results that the high south of the Alps is so stationary for $\tau<0$ in the $T_{\lambda \mathrm{AL}}$ cases. The line of vanishing pressure perturbation in Figure 6 hardly shifts its position between $\tau=-4$ days and $\tau=0$. This suggests that low-frequency motions play a role in these events. The reasons for the growth and decay of, say, the pressure perturbations during torque events have been discussed in Egger and Hoinka (2006) on the basis of a statistical vorticity equation applied to Greenland. Similar efforts had to be abandoned for
Mediterranean topography. The scale of these obstacles is too small for a reliable evaluation of the corresponding terms.

The perturbations moving towards the mountains from the northwest or west exhibit relatively little tilt westward in the vertical. However, this does not mean that temperature perturbations are unimportant. The sometimes rapid changes of $Q\left(z_{0}\right)$ with height $z_{\mathrm{o}}$ must be due to the temperature perturbations at low levels.

In principle, such torque calculations could be used to have a look at orographic cyclogenesis events (Trigo et al., 2002) which are known to occur south of the Alps, near the Atlas range (Alpert and Ziv, 1990) and near Asia Minor (e.g. Ziv et al., 2006). It is obvious that torques are exerted during this type of cyclogenesis. However, our approach is not well suited for such investigations because the correlation analysis gives equal weight to positive and negative events. Attempts to distinguish between positive and negative cases are reported in Egger and Hoinka (2007). Moreover, lee cyclogenesis events are

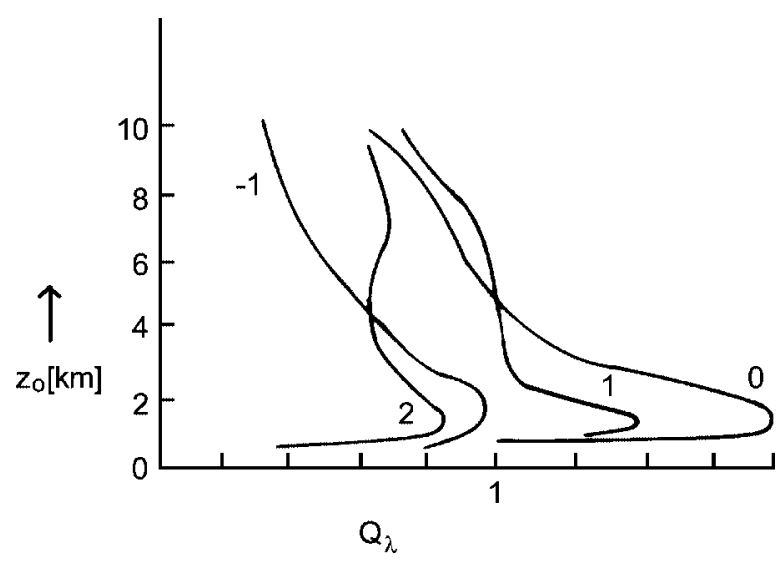

Figure 22. Torque covariance $Q_{\lambda}\left(z_{\mathrm{o}}\right)$ (Hadley) in winter for torque event $T_{\lambda \mathrm{AM}}$. The lag (days) is given by the number on each curve. 


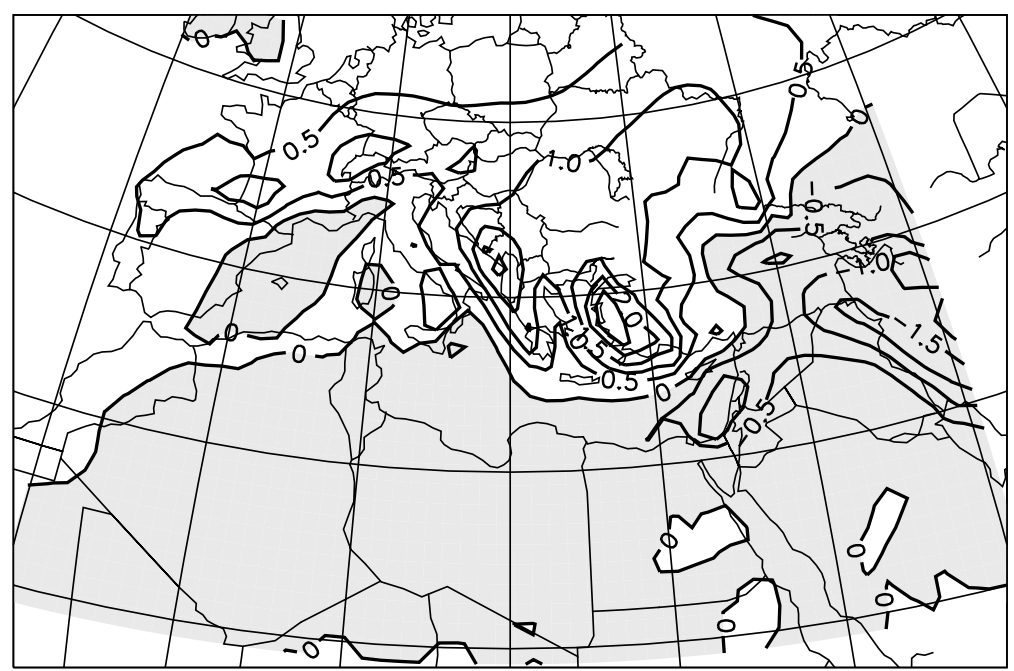

Figure 23. Covariance $C\left(T_{\lambda \mathrm{AM}}, R \mid \tau\right)$ of $T_{\lambda \mathrm{AM}}$ with precipitation $\left(\mathrm{mm} \mathrm{day}^{-1}\right)$ in winter at $\tau=0$. The contour interval is $0.5 \mathrm{~mm} \mathrm{day}^{-1}$, and negative values are shaded.

just part of the group of torque events contributing to the figures presented above.

The precipitation patterns found in the analysis can be explained mainly as orographically forced due to the interaction of the large-scale flow with the mountains of the Mediterranean. This means in turn that the release of latent heat leads to a reduction of the torques.

All in all, our analysis provides a fairly clear picture of the situations under which the transfer of angular momentum from the Earth to the atmosphere is strongest both for the zonal and the meridional component. The simple arguments relating to angular momentum transfer at a mountain (as underlying Figure 2) appear to explain at least the gross features of the torque events. Note, however, that the evolution of the events in time is missing in Figure 2. This scheme cannot predict the build-up and decay of the low-level pressure distribution simply because the pressure distribution of the large-scale wave is assumed uniform.

\section{References}

Alpert P, Ziv B. 1990. The Sharav cyclone: Observations and some theoretical considerations. J. Geophys. Res. 94(D15): 18495-18514

Bougeault P, Jansa A, Attie JL, Beau I, Benesch B, Benoit R, Bessemoulin P, Caccia JL, Campins J, Carissimo B, Champeaux JL, Crochet M, Druilhet A, Durand P, Elkhalfi A, Flamant P, Genoves A, Georgelin M, Hoinka KP, Klaus V, Koffi E, Kotroni V, Mazaudier C, Pelon J, Petitdidier M, Pointin Y, Puech D, Richard E, Satomura T, Stein J, Tannhauser D. 1993. The atmospheric momentum budget over a major mountain range: First result from the PYREX field program. Ann. Geophys. 11: 395-418.

Buzzi A, Tosi E. 1989. Statistical behavior of transient eddies near mountains and implications for theories of lee cyclogenesis. J. Atmos. Sci. 46: $1233-1249$.

De Viron C, Bizouard CH, Salstein D, Dehant V. 1999. Atmospheric torque on the Earth and comparison with angular momentum variations. J. Geophys. Res. 104(B3): 4861-4875.

Egger J. 1998. Mountain torque and Rossby wave radiation. J. Atmos. Sci. 55: 5937-2945.

Egger J, Hoinka KP. 1992. Fronts and orography. Meteorol. Atmos Phys. 48: 3-36.

Egger J, Hoinka KP. 2006. Dynamics of atmospheric regression patterns: regional mountain torque events. J. Atmos. Sci. 63 $1467-1482$.
Egger J, Hoinka KP. 2007. Mountain torque events in the Mediterranean. Adv. Geosci. 12: 1-4.

Egger J, Hoinka KP. 2008. Mountain torque events at the Tibetan Plateau. Mon. Weather Rev. 136: 389-404.

Egger J, Weickmann K, Hoinka KP. 2007. Angular momentum in the global atmospheric circulation. Rev. Geophys. 45: RG4007, doi 10.1029/2006RG000213.

Held IM. 1983. Stationary and quasi-stationary eddies in the extratropical troposphere: Theory. Pp. 127-167 in Large-scale dynamical processes in the atmosphere. Hoskins BJ, Pearce RP (eds.) Academic Press: London.

Iskenderian H, Salstein D. 1996. Regional sources of mountain torque variability and high-frequency fluctuations in atmospheric angular momentum. Mon. Weather Rev. 126: 1681-1694.

Lejenäs H, Madden R. 2000. Mountain torques caused by normal mode global Rossby waves, and the impact on atmospheric angular momentum. J. Atmos. Sci. 57: 1045-1051.

Livezey R, Chen W. 1983. Statistical field significance and its determinations by Monte Carlo techniques. Mon. Weather Rev. 111: 46-59.

Orlanski I, Gross B. 1994. Orographic modification of cyclone development. J. Atmos. Sci. 51: 589-611.

Smith RK. 1979. The influence of mountains on the atmosphere. Adv. Geophys. 21: 87-230.

Speranza A, Buzzi A, Trevisan A, Malguzzi P. 1985. A theory of deep cyclogenesis in the lee of the Alps. Modifications of baroclinic instability by localized topography. Part I. J. Atmos. Sci. 42: $1521-1535$.

Trevisan A, Ferranti L, Malguzzi P. 1988. Further developments of normal mode theory of lee cyclogenesis: Isentropic coordinate model. J. Atmos. Sci. 45: 3880-3888.

Trigo I, Bigg G, Davies T. 2002. Climatology of cyclogenesis mechanisms in the Mediterranean. Mon. Weather Rev. 130: 549-568.

Uppala SM, Kållberg PW, Simmons AJ, Andrae U, Da Costa Bechtold V, Fiorino M. Gibson JK, Haseler J, Hernandez A, Kelly GA, Li X, Onogi K, Saarinen S, Sokka N, Allan RP, Andersson E, Arpe K, Balmaseda MA, Beljaars ACM, Van de Berg L, Bidlot J, Bormann N, Caires S, Chevallier F, Dethof A, Dragosazac M, Fisher M, Fuentes M, Hagemann S, Hólm E, Hoskins BJ, Isaksen L, Janssen PAEM, Jenne R, McNally AP, Mahfouf J-E, Morcrette J-J, Rayner NA, Saunders RW, Simon P, Sterl A, Trenberth KA, Untch A, Vasiljevic D, Viterbo P, Woollen J. 2005. The ERA re-analysis. Q. J. R. Meteorol. Soc. 131: 2961-3012. Weickmann K. 2003. Mountains, the global friction torque and the circulation over the Pacific/North American region. Mon. Weather Rev. 131: 2608-2622.

Ziv B, Dagan U, Kushnir V, Roth CH, Enzel Y. 2006. Regional and global atmospheric patterns governing rainfall in the southern Levant. Int. J. Climatology 26: 55-75. 